\title{
Isolation, Biochemical Characterization and Ultrastructural Analysis of the Limbic System-Associated Membrane Protein (LAMP), a Protein Expressed by Neurons Comprising Functional Neural Circuits
}

\author{
Anna Zacco, Vilma Cooper, Peter D. Chantler, Susan Fisher-Hyland, Heather L. Horton, and Pat Levitt \\ Department of Anatomy, Medical College of Pennsylvania, Philadelphia, Pennsylvania 19129
}

The limbic system-associated membrane protein (LAMP) is a cell surface glycoprotein expressed by cortical and subcortical regions of the mammalian CNS that comprise or receive direct projections from limbic system structures. The early and restricted expression of LAMP has led to its postulated role in neural development. Purification and biochemical characterization of LAMP was performed in order to ascertain its relationship to other, well-defined cell surface proteins in the nervous system. Subcellular fractionation, immunoaffinity chromatography, and Western blots of rodent and bovine hippocampus revealed that LAMP is an integral membrane protein with a molecular mass of 64-68 $\mathrm{kDa}$ and a p/ of 5.2-5.5. Deglycosylation of LAMP indicates that it contains $\mathrm{N}$-linked high mannose or hybrid sugars and a minor amount of sialic acid. The LAMP protein exhibits an identical molecular mass in developing hippocampus and in several different brain regions in the adult. No cross-reactivity was obtained using the monoclonal antibody that recognizes the HNK-1 carbohydrate epitope, a complex sulfated moiety expressed on members of a large family of glycoproteins. Immunocytochemical analysis at the ultrastructural level reveals that LAMP immunoreactivity is exhibited by neurons in a stereotyped pattern throughout limbic system areas. Glial cells are not immunoreactive. In the adult, LAMP-immunoreactive membrane patches are present exclusively postsynaptically on neuronal somata and dendrites. Myelinated and unmyelinated axons are not stained in any brain region examined. Analysis of LAMP expression in the developing CNS during synaptogenesis demonstrates that LAMP is located on growing axons and both pre- and postsynaptically at forming terminal complexes. Double-labeling studies of the hippocampal neurons grown in vitro reveal that the LAMP epitope is extracellular and is expressed on neurofilament- and microtubule-associated protein 2-positive neurites. Cells expressing glial fibrillary acidic protein are not LAMP-immunoreactive. These results demonstrate that in the adult brain, LAMP is expressed almost exclusively by the postsynaptic (target) elements in limbic circuits, but that during development, all components of the

\footnotetext{
Received Feb. 6, 1989; revised June 19, 1989; accepted June 20, 1989.

This research was supported by NIMH grant MH45507, March of Dimes Basic Research grant 1-919, NSF grant BNS-8519647, and a fellowship from the Joseph and Esther Klingenstein Fund (P.L). Part of this work was carried out while P.L. was a National Down Syndrome Society scholar.

Correspondence should be addressed to Dr. Pat Levitt, Department of Anatomy, Medical College of Pennsylvania, 3200 Henry Avenue, Philadelphia, PA 19129. Copyright (C) 1990 Society for Neuroscience $0270-6474 / 90 / 010073-18 \$ 02.00 / 0$
}

surface of the growing neuron contain LAMP. The stereotyped anatomical pattern of expression of LAMP in the developing and mature brain and its biochemical characteristics suggest that LAMP is a unique, system-associated membrane glycoprotein that is distinct from previously identified, developmentally important cell surface proteins.

Cell surface molecules expressed in the developing nervous system appear to be important components in the regulation of cell-cell and cell-extracellular matrix adhesion (Edelman, 1984; Goodman et al., 1984; Rutishauser, 1984; Levitt, 1985; Lander, 1987; Dodd and Jessell, 1988; Harrelson and Goodman, 1988; Jessel, 1988; Rathjen, 1988; Rutishauser et al., 1988). These interactions may in turn regulate process outgrowth (Rathjen and Schachner, 1984; Fischer et al., 1986; Bastiani et al., 1987; Chang et al., 1987; Lagenaur and Lemmon, 1987; Harrelson and Goodman, 1988; Rathjen, 1988) and neuronal migration (Bronner-Fraser, 1985; Thierry et al., 1985; Antonicek et al., 1987; Edmondson et al., 1988), which ultimately lead to the formation of specific neural circuits. Several families of related cell surface proteins have been identified which appear to participate in some of these developmental events. The neural cell adhesion molecule (NCAM)-related glycoproteins appear to participate in cellular aggregation during neural crest formation (Thierry et al., 1985), axon fasciculation in the retinotectal pathway (Fraser et al., 1984; Silver and Rutishauser, 1984; Thanos et al., 1984; Rathjen et al., 1987a, b) and axon-target interactions in the neuromuscular pathway (Tosney et al., 1986). Their structural homology is likened to the immunoglobulin superfamily of membranc constitucnts (Williams, 1982, 1987; Rathjen, 1988), which includes NCAM, Thy-1, OX-2, the myelinassociated Po protein and more recently sequenced L.1 (Moos et al., 1988) and fasciclin II (Harrelson and Goodman, 1988). Another family of glycoproteins that is expressed on axons comprises molecules that express the L2/HNK-1 carbohydrate epitope (Rathjen, 1988). Glycoproteins such as L1 may directly regulate the amount and pattern of neurite outgrowth during development (Fischer et al., 1986; Lagenaur and Lemmon, 1987).

In some instances, these proteins are associated with specific components of the neuron. For example, glycoproteins have been identified that are highly concentrated in the growth cone fraction from developing brain (Ellis et al., 1985; Schlosshauer, 1985; Greenberger and Pfenninger, 1986; Meiri et al., 1986; Skene et al., 1986; Pfenninger, 1987) and, in the invertebrate, a family of glycoproteins, which is specifically inserted into the membrane of axons comprising different tracts, has becn identified (Bastiani et al., 1987; Patel et al., 1987; Snow et al., 1987). 
The surface protein M6 exhibits a developmentally regulated spatial distribution in the mouse optic nerve (Lund et al., 1986). M6 is expressed on all parts of optic axons at birth, but only in the optic fiber layer of the retina in the adult. TAG-1, a member of the HNK-1 carbohydrate-containing family (Abo and Balch, 1981; Rathjen, 1988), is inserted into the membrane of commissural axons in the spinal cord prior to their crossing the midline (Dodd et al., 1988). These data suggest that neurons regulate precisely membrane protein trafficking, presumably designed to concentrate molecules at sites in which specific cellular interactions occur. While some of these molecules continue to be expressed in mature neurons, their function in the adult remains unknown. Thus, 3 sites of regulation - expression, molecular modification, and spatial distribution - may be important for a neuron in modulating molecular interactions during development and in the adult.

We have recently identified a glycoprotein whose anatomical distribution in the mammalian CNS appears to be unique compared with other previously identified molecules (Levitt, 1984; Levitt et al., 1986; Horton and Levitt, 1988). The limbic systemassociated membrane protein (LAMP) is expressed on the surface (Levitt et al., 1986) of neurons comprising the cortical and subcortical regions of the limbic system, a part of the mammalian brain involved in behavior and memory. The initial biochemical characterization of LAMP suggested that it is an integral membrane protein that contains glycoconjugates, with a molecular mass of approximately 64,000 Da (Levitt et al., 1986). Upon the discovery of LAMP, we hypothesized initially that families of such functional system-associated molecules may exist in the mammalian brain and that they would mediate developmental events such as target recognition (Levitt, 1985). The interest in gaining a more detailed understanding of this protein has become even greater in view of a recent study in which a monoclonal antibody against LAMP was able to inhibit the axons of limbic neuron from innervating a normal target in vitro (Keller and Levitt, 1987; Keller et al., 1989). We undertook this study to gain a more detailed understanding of the molecular characteristics of LAMP and to determine whether this systemassociated protein is part of a previously identified family of surface glycoproteins or the first of a potentially new group of membrane-associated proteins that may mediate neural circuit formation. In addition, ultrastructural studies were performed to more clearly define the brain cell types that express LAMP in the adult brain, to determine the precise cellular localization of this unique glycoprotein, and to determine how the spatial distribution of LAMP changes during synaptogenesis.

\section{Materials and Methods}

Female Sprague-Dawley albino rats (Holtzman Farm, Madison, WI), housed in a 12-hr light-dark cycle with free access to food and water, were used for the biochemical and anatomical studies.

LAMP purification. LAMP was purified for biochemical characterization from approximately 80 rats ( 20 for each separate preparation) and from 5 bovine brains. The hippocampus from each side was dissected rapidly, homogenized under reduced conditions $(0.2 \% 2$-mercaptoethanol) in isotonic Tris buffer containing approximately $1 \mathrm{~m} \mathrm{su}$ crose and the following protease inhibitors: phenylmethylsulfonyl fluoride, $0.5 \mathrm{~mm}$; turkey egg trypsin inhibitor, $1.0 \mu \mathrm{g} / \mathrm{ml}$; aprotinin, 10 $\mu \mathrm{g} / \mathrm{ml}$. The homogenized material was filtered through cheesecloth and layered onto a discontinuous sucrose density gradient containing the following steps: $1.5 \mathrm{ml}$ each of $2,1.5$, and $1 \mathrm{M}$ sucrose; $3 \mathrm{ml}$ of the tissue homogenate, $1.5 \mathrm{ml}$ each of 0.75 and $0.5 \mathrm{M}$ sucrose and a top layer of $3 \mathrm{ml}$ of $0.11 \mathrm{M}$ sucrose. The gradient was centrifuged for $3 \mathrm{hr}$ at 27,000 $\mathrm{rpm}$ at $4^{\circ} \mathrm{C}$. Most of the LAMP immunoreactivity is found in a dense, particulate layer (see Results). The active fraction was then diluted 1:1 with isotonic Tris buffer and centrifuged at $100,000 \times g$ for $30 \mathrm{~min}$, and the pellet washed with Tris-buffered saline (TBS) to remove the 2 -mercaptoethanol. The activity in the pellet was solubilized with $4 \%$ Chaps detergent in TBS for $4 \mathrm{hr}$. In some cases, the solubilized material was partially purified on Sephacryl S-300 high-resolution matrix (Pharmacia). Fractions containing immunoreactivity (65-75,000 Da range) were further purified on an immunoaffinity column of anti-LAMP antibody crosslinked to a protein A-Sepharose matrix (Pharmacia; Schneider et al., 1982). Specific immunoreactivity, representing affinity-purified LAMP, was eluted using $0.1 \mathrm{~m}$ sodium borate buffer, $\mathrm{pH} 10.0$, and immediately neutralized with $0.5 \mathrm{M}$ sodium phosphate. Fractions were combined, dialyzed against $10 \mathrm{~mm}$ sodium phosphate buffer, $\mathrm{pH} 7.0$, and then lyophilized. The lyophilized material was rehydrated and iodinated with $0.25 \mathrm{mCi}$ of ${ }^{125} \mathrm{I}$-sodium iodide (New England Nuclear), using Iodobeads (Pierce Chemical). The iodinated protein was passed over a Sephadex G-75 column and 16 fractions were collected and then run on a $10 \%$ SDS-PAGE gel along with the following molecular-mass markers: myosin, $200 \mathrm{kDa}$; transferrin, $78 \mathrm{kDa}$; ovalbumin $45 \mathrm{kDa}$, using the standard Laemmli system (1970). Gels were silver stained (Morrissey, 1981), dried, and placed against Kodak X-Omat AR film to visualize the affinity-purified protein(s).

Dot-blot assay. A modification of a standard dot-blot assay (Hawkes et al., 1982) was used to detect antibody-antigen immunoreactivity. Two $\mu$ l aliquots of antigen were spotted onto nitrocellulose strips, dried for 2-24 hr, and subsequently blocked in 10\% horse serum in PBS for $1 \mathrm{hr}$. The samples were incubated overnight at $4^{\circ} \mathrm{C}$ with a $1: 100$ dilution of anti-LAMP or 1:100 dilution of anti-HNK-1 (American Type Culture Collection Hybridoma TIB-200). The nitrocellulose was washed extensively and then incubated at room temperature for $1 \mathrm{hr}$ with HRP-conjugated rabbit anti-mouse IgG (Accurate Chemical) or goat anti-mouse IgM (Southern Biotechnology), diluted 1:250-500. After washing with PBS, the peroxidase was visualized using 4-chloro-1-napthol as substrate.

Two-dimensional gel electrophoresis. Two-dimensional polyacrylamide gel electrophoresis was performed using techniques derived from those of O'Farrell (1975). The first dimension was an isoelectric focusing gel ( $200 \mu$ l capillary tubes) run under denaturing conditions ( $9.5 \mathrm{M}$ urea). $\mathrm{pH}$ gradients were maintained by the presence of Pharmalyte (Pharmacia-LKB Biotechnology) ampholines, employed at a 10-fold dilution of the concentration supplied by the manufacturer. We have used gradients made up of $100 \% \mathrm{pH} 3.5-10$ ampholines and of a mixture made up of $80 \%$ pH $5-8$ plus $20 \% \mathrm{pH} 3.5-10$ ampholines. The second dimension was a $10 \%$ acrylamide/SDS slab gel. Lyophilized samples of ${ }^{125}$ I-labeled LAMP were resuspended in 10-20 $\mu \mathrm{l}$ of isoelectric focusing sample buffer (O'Farrell, 1975) prior to loading onto the first-dimension gel. Following electrophoresis in the second dimension, the gel was fixed ( $10 \%$ methanol, $7.5 \%$ acetic acid), dried, and exposed for autoradiography (Kodak X-Omat AR film).

Enzymatic deglycosylations. Indinated, purified LAMP, containing protease inhibitors $0.5 \mathrm{mM}$ PMSF, $1.0 \mu \mathrm{g} / \mathrm{ml}$ turkey egg trypsin inhibitor, and $10 \mu \mathrm{g} / \mathrm{ml}$ aprotinin was treated to the following enzymatic digests. Iodinated protein $(8.3 \mu \mathrm{g}$ at $0.33 \mu \mathrm{g} / \mu \mathrm{l})$ was incubated with 0.01 $\mathrm{U}$ of endoglycosidase $\mathrm{D}$ and $0.01 \mathrm{U}$ of endoglycosidase $\mathrm{H}$ for $17-18 \mathrm{hr}$ at $37^{\circ} \mathrm{C}$. The reaction was terminated by the addition of SDS-PAGE sample buffer. Iodinated protein was also treated with the exoglycosidase enzyme Neuraminidase $\left(0.5 \mathrm{U}\right.$; Sigma) for $18 \mathrm{hr}$ at $37^{\circ} \mathrm{C}$ and stopped by the addition of SDS-PAGE sample buffer. Each of the 3 enzymatic digests were examined in parallel with undigested affinity-purified protein by SDS gel electrophoresis ( $10 \%$ acrylamide), after which the gel was dried and placed against $\mathrm{x}$-ray film.

Western blot analysis. Solubilized membrane fractions containing LAMP immunoreactivity were prepared from rat (14-18 $\mu \mathrm{g} / \mu \mathrm{l}) \mathrm{hip}-$ pocampus, amygdala, cerebellum, and bovine hippocampus $(20 \mu \mathrm{g} / \mu \mathrm{l})$, diluted $1: 1$ with a modified SDS-PAGE sample buffer containing $0.1 \%$ SDS and incubated overnight at room temperature. Treatment of the solubilized membrane fraction with standard sample buffer (1-2\% SDS) or boiling destroys immunoreactivity with the monoclonal antibody. The soluble LAMP preparations from rat $(110 \mu \mathrm{g})$ and bovine $(200 \mu \mathrm{g})$ were run on $10 \%$ SDS-PAGE gels using color-coded molecular mass standards (Amersham). The Western transfer (Towbin et al., 1979) was performed using a semidry method on a Polyblot apparatus (American Bionetics). The proteins were transferred to nitrocellulose $(0.45 \mu \mathrm{m}$ pore, Schleicher and Schuell) for $30 \mathrm{~min}$ at $0.2 \mathrm{~A}$ (constant voltage). The nitrocellulose was blocked for $1 \mathrm{hr}$ at room temperature in $10 \%$ horse 
serum in PBS and incubated in a 1:100 dilution of anti-LAMP or 1:100 dilution of anti-HNK-1 overnight at $4^{\circ} \mathrm{C}$. Following extensive washing, the nitrocellulose sheet was incubated in HRP-conjugated goat anti-mouse IgG or IgM (Southern Biotechnology), diluted 1:250-500. The nitrocellulose was washed extensively and immunoreactivity visualized using 4-chloro-1-napthol as the substrate.

To determine whether LAMP immunoreactivity was present in a multimeric form, Chaps-solubilized hippocampal membranes were prepared as noted above, in the absence of 2 -mercaptoethanol. The nonreducing conditions were followed throughout this experiment by performing Western blot analysis on 10\% SDS-PAGE without the 2-mercaptoethanol.

Protein assay. The BCA protein assay kit (Pierce Chemical) was used to estimate protein concentration, using BSA as a standard.

Immunocytochemistry. For immunocytochemical staining of LAMP (Levitt, 1984; Horton and Levitt, 1988), adult and early postnatal rats were deeply anesthetized with sodium pentobarbitol (Nembutol; $40 \mathrm{mg}$ / $\mathrm{kg}$ ) and transcardially perfused with a brief saline rinse followed by $0.25-1$ liter of $4 \%$ paraformaldehyde, $0.1 \%$ glutaraldehyde in $0.1 \mathrm{M}$ sodium phosphate buffer, $\mathrm{pH}$ 7.2. For the electron microscopic studies (Levitt et al., 1981; Horton and Levitt, 1988), the brains were postfixed in situ for $6 \mathrm{hr}$ and the brain areas used for the analysis were dissected and sectioned at 50-100 $\mu \mathrm{m}$ on a Vibratome (Oxford Instruments). Sections were collected in $0.1 \mathrm{~m}$ sodium phosphate-buffered saline (PBS; pH 7.2), rinsed extensively, and incubated for $48 \mathrm{hr}$ at $4^{\circ} \mathrm{C}$ in a $1: 2000$ dilution of the anti-LAMP monoclonal antibody, prepared from sodium sulfate precipitates of hybridoma culture supernatants. Following extensive washing in PBS, the sections were incubated for $2 \mathrm{hr}$ in a 1:100 dilution of HRP-conjugated goat anti-mouse IgG (Accurate Scientific). All antibody incubations were done in the presence of $5 \%$ normal swine serum (Accurate Scientific). A monoclonal antibody of the same isotype (IgG2a) as anti-LAMP was used as the primary antibody control. Sections were washed in PBS following incubation in the secondary antibody and HRP localized using a $0.3 \%$ solution of 3,3'-diaminobenzidine tetrahydrochloride in an ammoniated phosphate buffer (Fridovich, 1963) containing $0.001 \% \mathrm{H}_{2} \mathrm{O}_{2}$. The reacted sections were rinsed in PBS, mounted for brief light microscopic examination, osmicated $\left(1 \% \mathrm{OsO}_{4}\right.$, $30 \mathrm{~min}$ ), dehydrated in a graded series of alcohols and propylene oxide, and processed for plastic embedding (Embed 812; Polaron). The Vibratome sections were flat-mounted between glass slides coated with Miller Stephenson Release Lubricant 122 to facilitate removal of the slides and tissue following hardening of the plastic (method from $\mathbf{M}$. Siegel and C. Shatz, Stanford University, Palo Alto, CA). The areas containing LAMP immunoreactivity were excised under a dissecting microscope and mounted on plastic blocks using cyanoacrylate cement. One-micron-thick plastic sections were collected and examined for regions of staining prior to thin sectioning. Thin sections, 700-900 $\AA$ were collected within $4 \mu \mathrm{m}$ from the surface of the block, mounted onto 150 mesh copper grids, and analyzed on a JEOL $100 \mathrm{CX}$ electron microscope. In most cases, counterstaining with lead citrate and uranyl acetate was not performed to facilitate the visualization of the HRP reaction product along the surfaces of the immunoreactive cells. Immunofluorescence was performed using an identical staining procedure on cryostat-sectioned brains (Levitt, 1984).

Primary cell cultures. Primary brain cell cultures were prepared from embryonic day (E) 16 hippocampi. The tissue was dissected in Earle's Balanced Salt Solution, freed of meninges, and dissociated into a singlecell suspension using a $0.2 \%$ collagenase/dispase solution (Worthington). Cells were plated onto polylysinated glass coverslips in 24 well plates containing Eagle's Basal Medium supplemented with $20 \mathrm{~mm}$ L-glutamine, $6.5 \mathrm{mg} /$ liter glucose, $10 \%$ fetal calf serum, and $1 \%$ penicillin/streptomycin. LAMP immunolocalization was performed on live cultures or specimens fixed briefly in $2 \%$ paraformaldehyde in $0.1 \mathrm{M}$ sodium phosphate buffer $(\mathrm{pH} 7.2)$. The monolayer cultures were incubated in a 1:150 dilution of the anti-LAMP monoclonal antibody for $3 \mathrm{hr}$ at room temperature, washed, and incubated in a 1:50 dilution of rhodamine-conjugated goat anti-mouse IgG (Jackson Immunoreagents). Coverslips were inverted onto a drop of $10 \%$ glycerol in PBS containing $p$-phenylenediamine to retard fading (Platt and Michael, 1983). Double staining of cultures also was performed with a rabbit polyclonal antiserum against microtubule-associated protein 2 (MAP 2; a gift from Dr. Itzhak Fischer, E. K. Shriver Center, Waltham, MA), a rabbit polyclonal antibody against glial fibrillary acidic protein (GFAP; a gift from Dr. Lawrence Eng, V.A. Medical Center, Palo Alto, CA), and a mouse monoclonal antibody (IgM isotype) against the $200 \mathrm{kDa}$ neurofilament
(NF-H) protein (K. R. Pennypacker, I. Fischer, and P. Levitt, unpublished observations). Live cultures stained for LAMP were subsequently fixed with paraformaldehyde and incubated in a 1:100 dilution of antiMAP-2, 1:150 dilution of anti-GFAP or 1:50 dilution of anti-NF. Immunolocalization of the MAP-2 and GFAP was performed using fluorescein-conjugated swine anti-rabbit IgG (Accurate Scientific). An isotype-specific fluorescein-conjugated anti-mouse IgG2a (for LAMP localization) was used in combination with rhodamine-conjugated antimouse IgM (Southern Biotechnology).

\section{Results}

\section{Detection of LAMP as an integral membrane protein}

Previous light and electron microscopic evidence suggested that most of the detectable LAMP immunoreactivity was present along the membranes of neurons in limbic system regions (Levitt, 1984; Levitt et al., 1986; Horton and Levitt, 1988). In order to document this at the molecular level, we performed several experiments to determine the subcellular fractions that contain LAMP immunoreactivity and the requirements for solubilization. Initial fractionation of the hippocampus on a discontinuous sucrose gradient results in almost all LAMP immunoreactivity present in a particulate layer at the $1 \mathrm{M}$ sucrose step (Fig. 1), with only a small amount of specific activity in the soluble interfaces between sucrose steps. This is probably due to some contamination during removal of each step, since $100 \%$ of the LAMP immunoreactivity can be pelleted at $100,000 \times$ $g$. This particulate activity was neither soluble in high salt nor extremes of $\mathrm{pH}$, suggesting that LAMP is indeed an integral membranc protein. This was confirmed in an experiment in which Triton X-114 was used to partition integral and peripherally associated membrane proteins (Bordier, 1981). The solubilization of LAMP using this detergent resulted in all of the detectable immunoreactivity being segregated in the bottom layer of the partition (data not shown). This separation is indicative of integral membrane proteins (Bordier, 1981). Finally, only detergent treatment is able to release LAMP immunoreactivity from the membrane pellet. This solubilization, however, is not complete, resulting in some activity remaining in the pellet even after several days of detergent treatment (Fig. 1). Detergents such as Triton $X-100$ and NP-40 result in similar degrees of solubilization from the hippocampal membranes, but immunoreactivity is greatly diminished. Each of the solubilization characteristics for LAMP using the rat hippocampus are also expressed in material isolated from rat amygdala, cerebellum, and bovine hippocampus.

\section{Identification and purification of LAMP}

Several approaches were utilized in this study to identify and purify the membrane constituent that represents LAMP. Both affinity purification of solubilized rat hippocampal membrane proteins and Western blot analysis reveal that LAMP is a single protein that migrates between $64-68,000 \mathrm{Da}$ on $10 \%$ SDS-polyacrylamide gels (Figs. 2, 3). Identical profiles are visualized on Western blots using the bovine hippocampus, rat amygdala, and cerebellum and hippocampus at 2 different postnatal ages. In addition, a single protein band of identical molecular mass is detected in both reducing and nonreducing conditions (cf. Fig. $2, A$ and $B$ ). In some instances, an immunoreactive band of greater than $200 \mathrm{kDa}$ can be seen (Fig. 2, C, D). This may be due to the relatively mild conditions (no boiling, $0.1 \%$ SDS in sample buffer) under which the solubilized protein fraction is run in order to preserve immunoreactivity. Furthermore, fractionation of affinity-purified LAMP, isolated under reduced con- 
Figure 1. Dot-blot assays of LAMP immunoreactivity in different fractions of a discontinuous sucrose gradient (right side) and following solubilization of one of the particular fractions from the gradient (left side). $E$ refers to the experimental strip incubated with primary and secondary antibody, $C$ refers to the control (background) strip incubated only with HRP-conjugated secondary antibody. Note the high level of activity in the initial homogenate (top square) and in the most dense particulate fraction (second from bottom of strip). Some specific immunoreactivity is present in the large, middle soluble phase, but the control spot also contains some nonspecific background activity. Left side: 1, hippocampal homogenate; 2 , dense particulate layer from sucrose gradient; 3, supernatant from 100,000 $\times g$ spin of sample in $2 ; 4$, pellet from $100,000 \times g$ spin of sample in $2 ; 5$, buffer wash of pellet; 6 , supernatant of Chaps-solubilized pellet; 7 , pellet after Chaps solubilization. Note the intense immunoreactivity in membrane pellet (4) and the lack of activity in the supernatant (3). Detergent-solubilization releases LAMP immunoreactivity (6), but a substantial amount remains in the pellet (7).

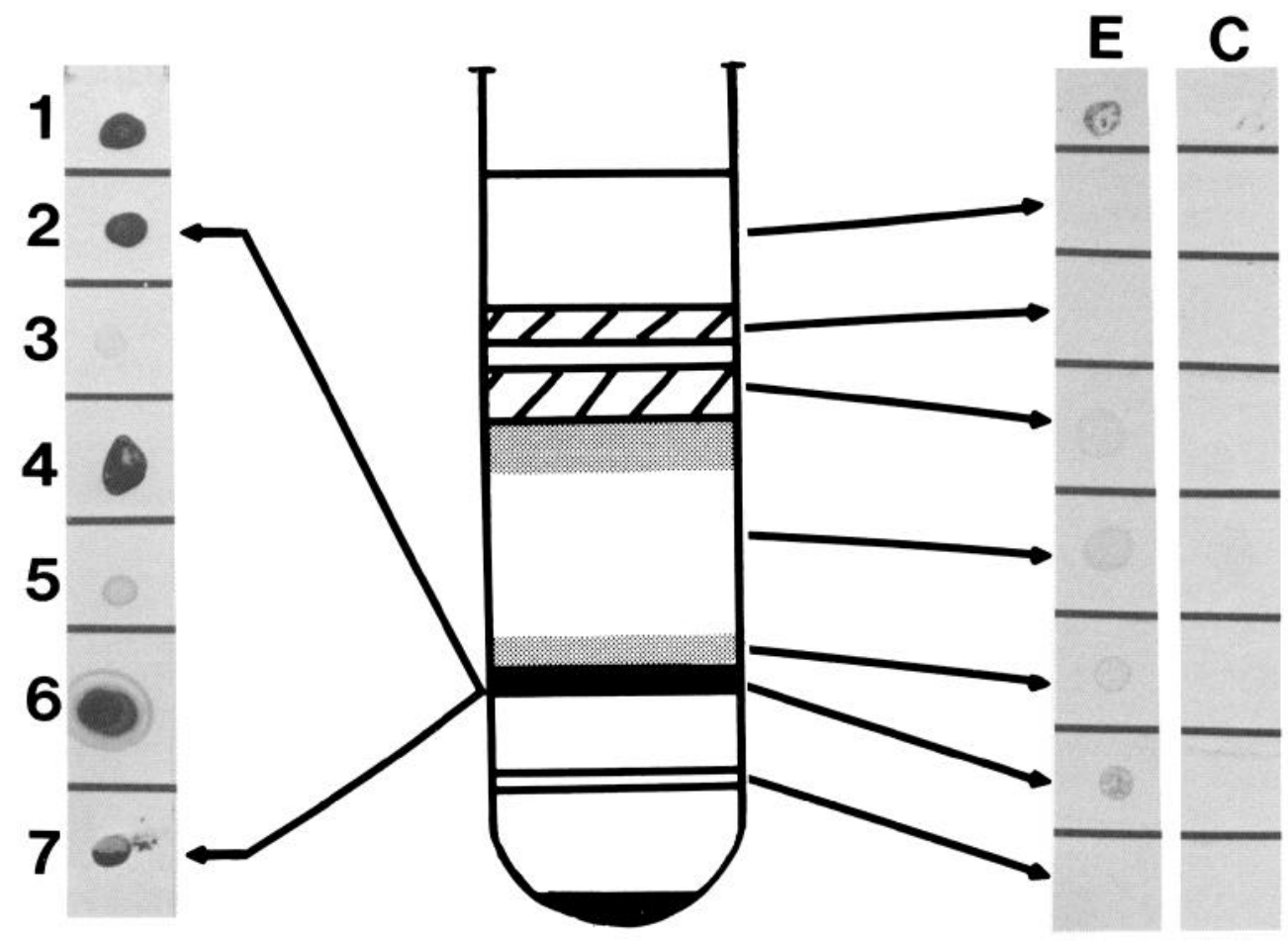

ditions with high detergent concentration ( $>2 \%$ Chaps), by HPLC on a Superose 12 column (Pharmacia) results in all activity in the 68-72 kDa range (data not shown). SDS-PAGE analysis of immunoaffinity-purified, detergent-solubilized membranes from rat hippocampus yields a single band of identical molecular mass (Fig. 3) as identified by Western blots from the crude membrane protein mixture. The results from the 2 different protocols indicate that the monoclonal antibody recognizes a single protein that is conserved phylogenetically and between several brain regions that exhibit reactivity by immunocytochemical methods. Data from the 2-dimensional gel electrophoresis of the immunoaffinity-purified protein also supports our conclusion that LAMP is a single protein. This gel analysis reveals that LAMP migrates as a single spot (Fig. 4), with a molecular mass of approximately $68,000 \mathrm{Da}$ and a $\mathrm{p} I$ of $5.2-5.5$.

Several experiments were performed to determine the basic characteristics of the epitope on LAMP that is recognized by the monoclonal antibody. Both brief boiling and exposure to greater than $0.5 \%$ SDS results in a complete loss of immunoreactivity on the dot-blot assay. Protein digestion with bacterial strain V-8 protease, papain, and pepsin also results in a loss of cross-reactivity. Deglycosylation of LAMP with several enzymes does not result in changes in cross-reactivity (see below). Each of these treatments suggests that the monoclonal antibody recognizes the peptide portion of the molecule and that this interaction may be conformation dependent.

\section{LAMP carbohydrate}

Previous data revealed that LAMP immunoreactivity can be retained on a wheat germ agglutinin column, suggesting the presence of carbohydrate groups (Levitt et al., 1986). In addition, the periodic acid-Schiff (PAS) reagent, which specifically reacts with carbohydrate moieties (Kasten, 1960; Fairbanks et al., 1971), stains immunopurified LAMP following SDS-PAGE. In order to determine the type of carbohydrate modification on LAMP and the relative contribution of glycosylation to the molecular mass, several enzymatic digestions were performed. Endoglycosidase $\mathrm{H}$ (endo $\mathrm{H}$ ) and neuraminidase treatments both result in small, but detectable molecular-mass shifts of iodinated LAMP (Fig. 5). Endo $\mathrm{H}$ cleaves $\mathrm{N}$-linked, high mannose or hybrid-type sugars (Tarrentino et al., 1978). This enzyme results in a molecular-mass shift of approximately $7-10 \%$ and causes the normally compact band to run more diffusely. Neuraminidase cleaves sialic acid residues and results in a smaller shift in molecular mass and a characteristic tightening of the protein band.

\section{Comparison of LAMP and HNK-1 related molecules}

While no other reports currently exist for a membrane protein that is distributed anatomically as we have described for LAMP, we wanted to determine the potential relationship of this unique system-associated membrane protein with other known neural glycoproteins. We utilized a monoclonal antibody that crossreacts with the L2/HNK-1 carbohydrate, an epitope that is shared by a large family of adhesion-associated brain glycoproteins, including NCAM, L1, NILE, L2, chick 8D9, G4, and NgCAM (Kruse et al., 1984; Wolff et al., 1987; Rathjen, 1988) and TAG-1 (Dodd et al., 1988). We found that affinity-purified LAMP, while reacting on a dot-blot assay with anti-LAMP, exhibits no specific immunoreactivity with anti-HNK-1 (Fig. 6). In addition, Western blot analysis of solubilized hippocampal membranes, using both anti-LAMP and anti-HNK-1, reveals that none of the bands recognized by the HNK-1 antibody correspond in molecular mass to the protein detected by anti-LAMP. 


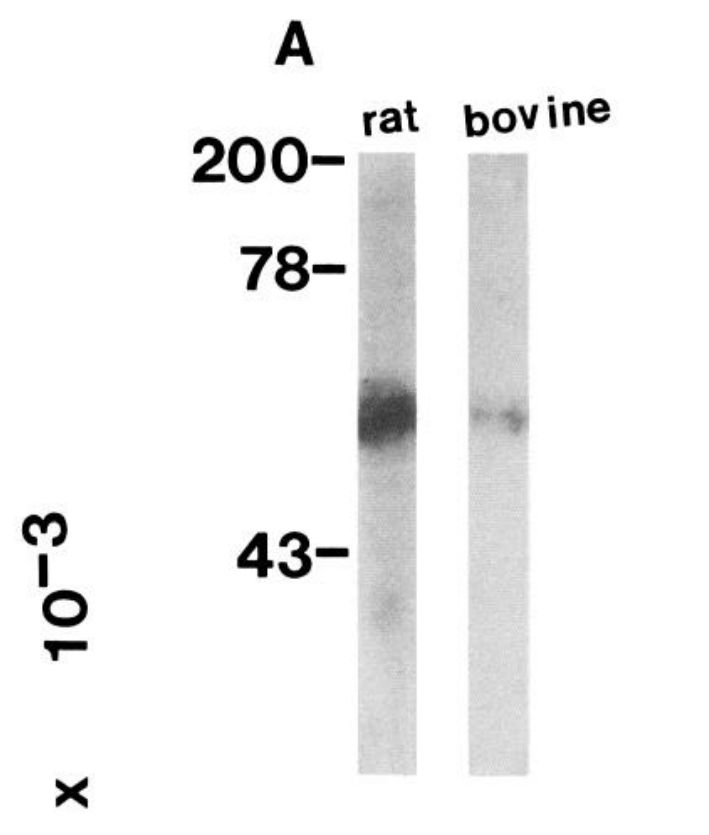

B
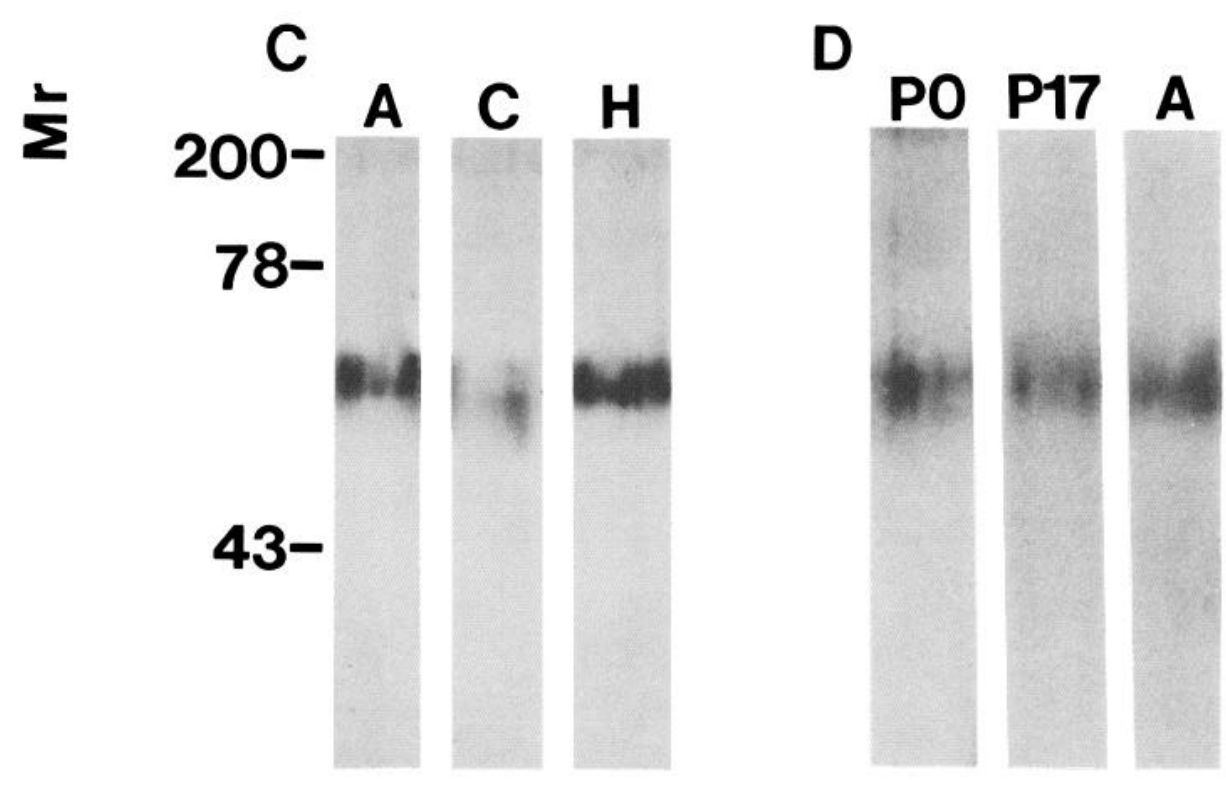

\begin{abstract}
Figure 2. A, Western transfer of Chapssolubilized membranes from adult rat and bovine hippocampi. Note the specific LAMP immunoreactivity is restricted to a single band, corresponding to a molecular mass of $64-68 \mathrm{kDa}$. $B$, Western transfer run under nonreducing conditions, using solubilized rat hippocampal membranes that were isolated in the absence of 2-mercaptoethanol. Note that LAMP exhibits an identical molecular mass under reducing $(A)$ or nonreducing $(B)$ conditions. $C$, Western transfer of Chaps-solubilized membranes from adult rat amygdala $(A)$, cerebellum $(C)$, and hippocampus $(H)$. The sample from the cerebellum was loaded at twice the protein concentration of the other samples. LAMP immunoreactivity from each of the 3 brain regions corresponds to a single protein band of identical molecular mass. The immunoreactivity in the cerebellum runs more irregularly (possibly due to total protein overloading) and is considerably less, even with the higher protein loading. $D$, Immunoblot of crude hippocampal membranes from $\mathrm{P} 0, \mathrm{P} 17$, and adult $(A)$ rat. Note the single band of identical molecular mass (64-68 kDa) localized at each age.
\end{abstract}

\section{LAMP distribution in adult neurons}

Regions of the lateral perirhinal cortex, hippocampus, anterior thalamic nuclei, preoptic area of the hypothalamus, septum, nucleus of the solitary tract, and lamina II of the dorsal horn were analyzed for LAMP immunoreactivity. These are all regions that previously had been shown to express LAMP (Levitt, 1984) and that comprise classic limbic system regions or receive direct limbic system afferents (Horton and Levitt, 1988). At the light microscopic level, LAMP staining is most prominent within the neuropil and pericellularly, outlining the silhouettes of cells in each region (Fig. 7). Punctate LAMP immunoreactivity usually is prominent along dendritic shafts (Fig. 7, $A, B$ ) and is most obvious in regions where the dendrites are oriented, for example, the cerebral cortex (Fig. 7A). LAMP immunoreactivity is not evident in fiber tracts in the adult, contrary to our findings in developing brain (Figs. $7 C ; 8, A, B$; see also Levitt et al.,
1986; Horton and Levitt, 1988). In semithin plastic sections, the surface distribution of immunoreactivity is more evident (Fig. 8C). LAMP staining appears to completely outline neuronal somata and can be followed along the proximal dendrites of large neurons. While it is difficult to discern whether all neurons in an immunoreactive limbic region express LAMP, different neuronal cell types in each immunoreactive brain area are LAMP-positive. This is most evident in the cerebral cortex, where immunoreactivity is present on neurons throughout layers II-VI.

Ultrastructural analysis reveals that LAMP immunoreactivity is present mostly at the cell surface (Figs. 9-11). In each region examined, only neurons are immunoreactive, and, in contrast to the light microscopic images, LAMP staining appears only as small, dark, granular patches along the membranes of neurons. Glial cells, even those in direct apposition to immunoreactive neurons, are not LAMP-positive (Fig. 10B). Intracel- 


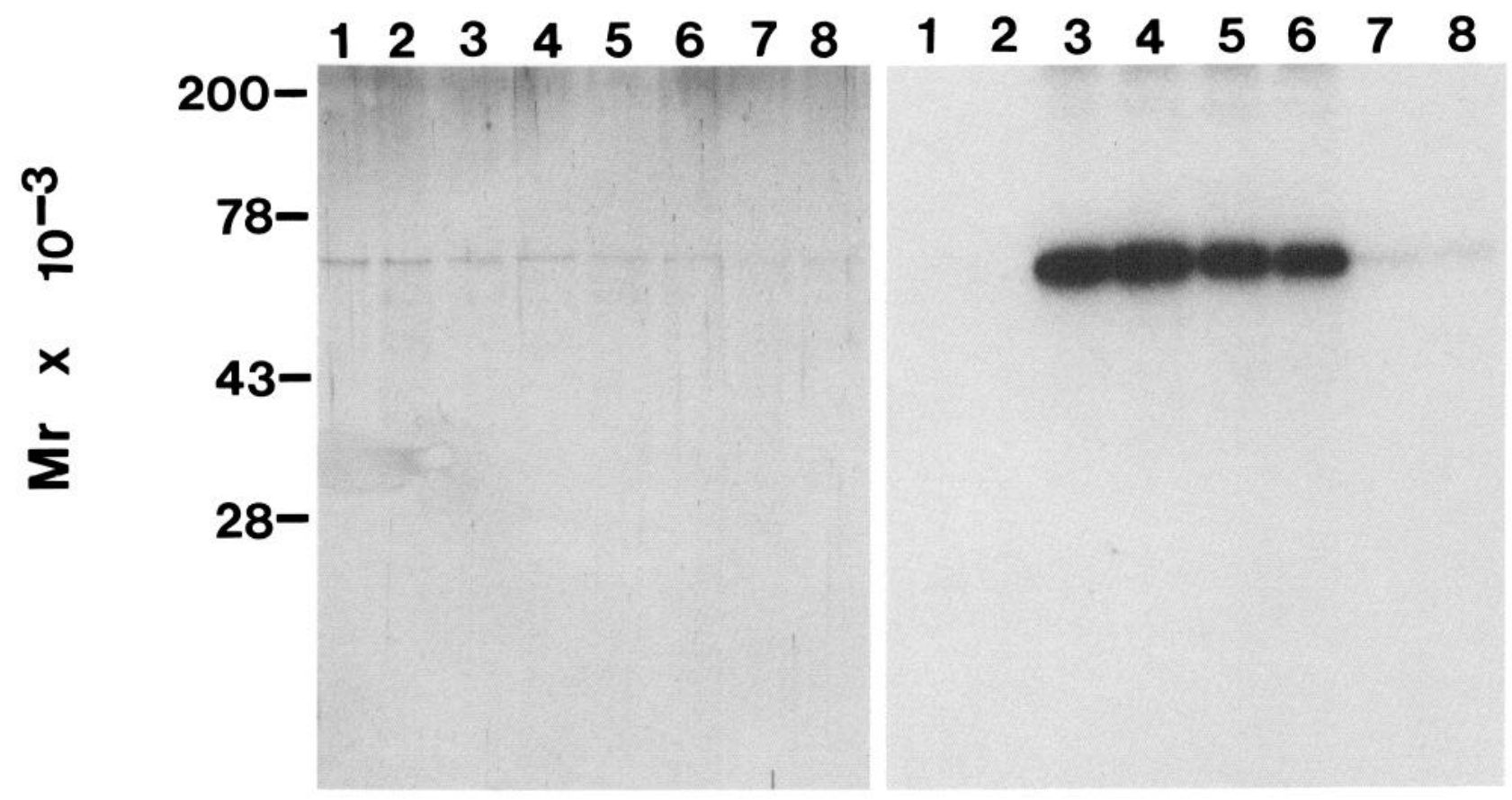

Figure 3. One-step immunoaffinity purification of LAMP from Chaps-solubilized hippocampal membranes. Elution pattern is from a Sephadex G-75 column on which the eluted sample from the anti-LAMP immunoaffinity column was run. Solubilized hippocampal membranes were first passed over the affinity column and then iodinated. Left panel, Silver-stained gel in which a single band is seen in each of the eluted fractions. This band does not correspond to the iodinated hippocampal proteins, since it is present in fractions ( 1 and 2$)$ in which there is no radioactivity (right panel). This band may represent a small amount of anti-LAMP antibody which is eluted from the protein A column nonspecifically. A single, iodinated protein band, approximately $64-68 \mathrm{kDa}$, is seen on the autoradiogram (right panel) following a 1 week exposure. This immunopurified protein exhibits anti-LAMP cross-reactivity on a dot-blot assay (see Fig. 11). The small amount of radioactivity present at the interface between the stacking and separating gel (top of the autoradiogram) represents iodinated protein that failed to enter the separating gel.

lular membranes in the LAMP-stained neurons, including the rough endoplasmic reticulum and Golgi apparatus, are not immunoreactive (Figs. 10, 11). Since the epitope recognized by anti-LAMP is contained in the peptide portion of the molecule (see above), this suggests that this part of the polypeptide is inaccessible to the antibody until LAMP is inserted into the plasma membrane.

As noted above, the neuropil in each region contains the

Figure 4. Autoradiogram of 2-dimensional gel in which the specifically eluted fraction from the anti-LAMP immunoaffinity column was run. Note the presence of a single spot at approximately $68 \mathrm{kDa}$, migrating with a $\mathrm{p} I$ of $5.2-5.5$. The small band of radioactivity seen at the top of the autoradiogram represents protein that did not enter the separating gel in the second dimension.

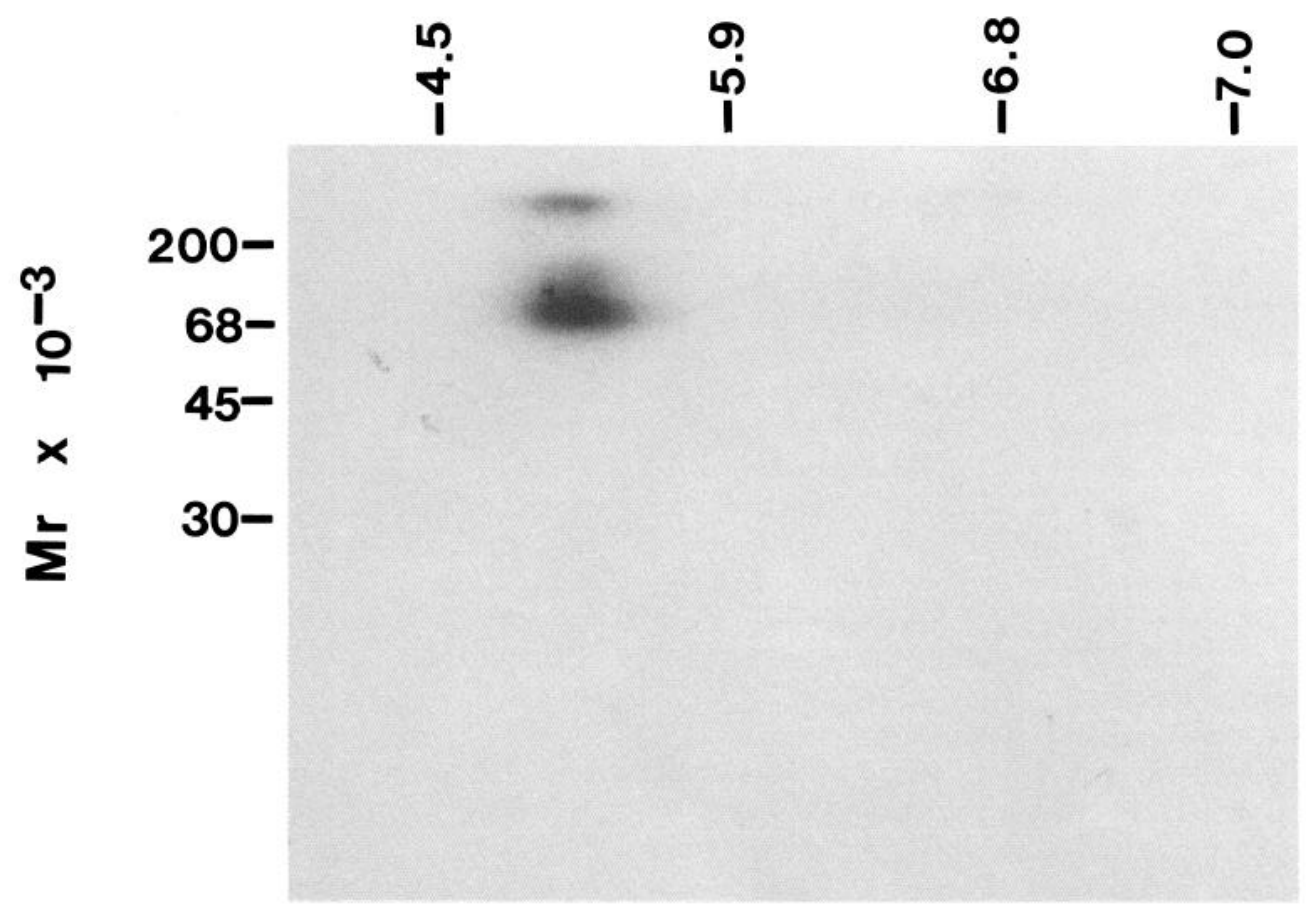




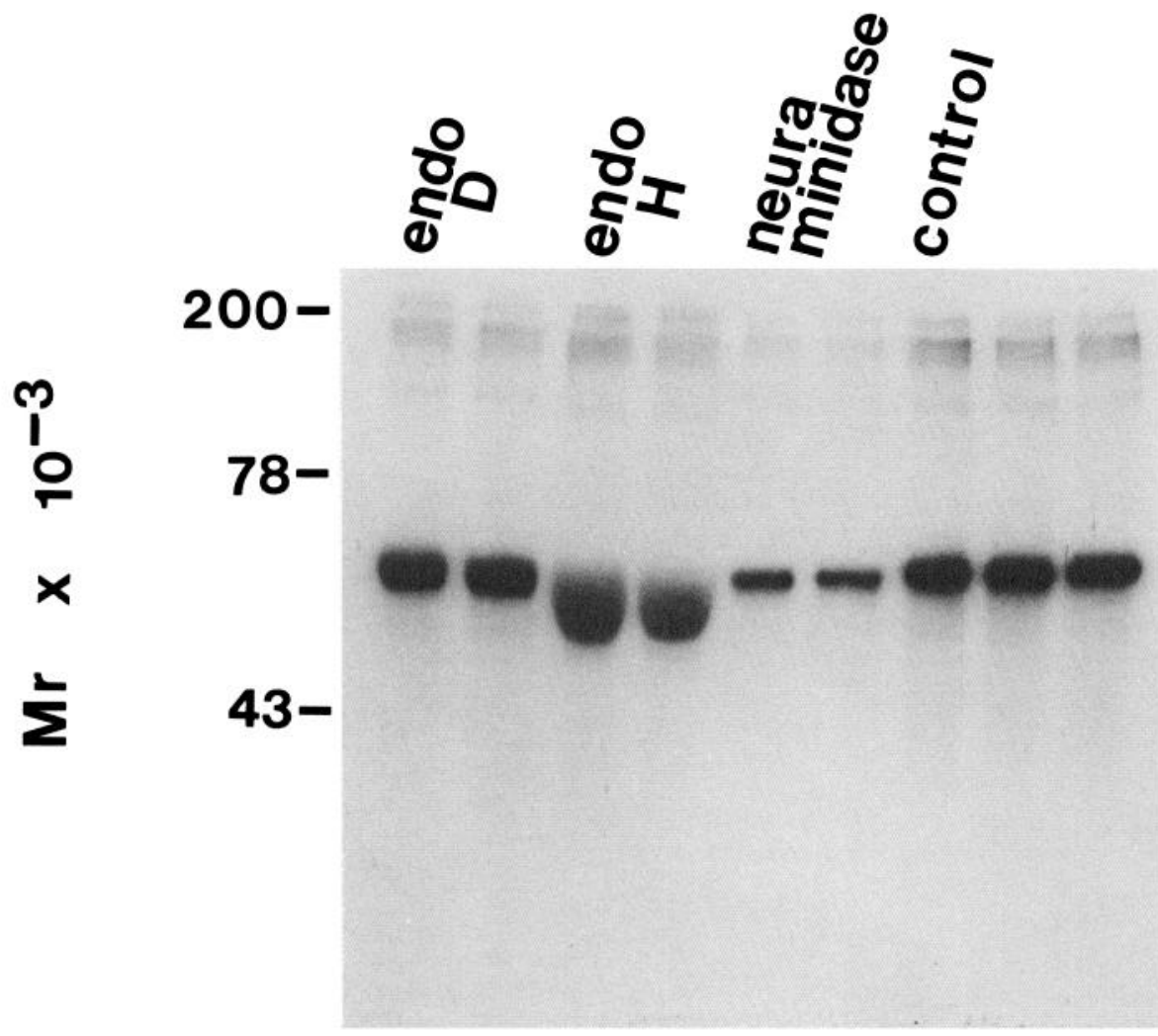

Figure 5. Deglycosylation of immunoaffinity-purified LAMP. Iodinated LAMP was treated with endoglycosidase $\mathrm{D}$ (endo $D$ ), endoglycosidase $\mathrm{H}$ (endo $H$ ), or neuraminidase and then run on $10 \%$ SDS-PAGE. The autoradiogram was exposed for 1 week. The endo D treatment did not result in any shift in molecular mass compared with the untreated, control LAMP. Endo H resulted in a small shift in molecular mass and a broadening of the band. The neuraminidase treatment caused only a tightening of the band following SDSPAGE.

heaviest immunoreactivity. Ultrastructural analysis demonstrates that LAMP staining is present almost exclusively on dendrites. Both myelinated and unmyelinated axons are not stained in regions containing immunoreactive neuronal somata and dendrites (Fig. 11), and this supports our previous immunoassay data on fresh, unfixed tissues in which the rostral corpus callosum and fimbria/fornix do not express any LAMP im- munoreactivity (Horton and Levitt, 1988). The LAMP staining on the proximal dendrites is distributed in discrete patches, in a manner similar to that visualized on cell bodies (Fig. 11, $A$, $B$ ). Cross sections of smaller, more distal dendrites reveal that LAMP immunoreactivity is also distributed in discrete patches, not usually forming a complete ring of staining along the entire membrane surface. While the HRP reaction product is present

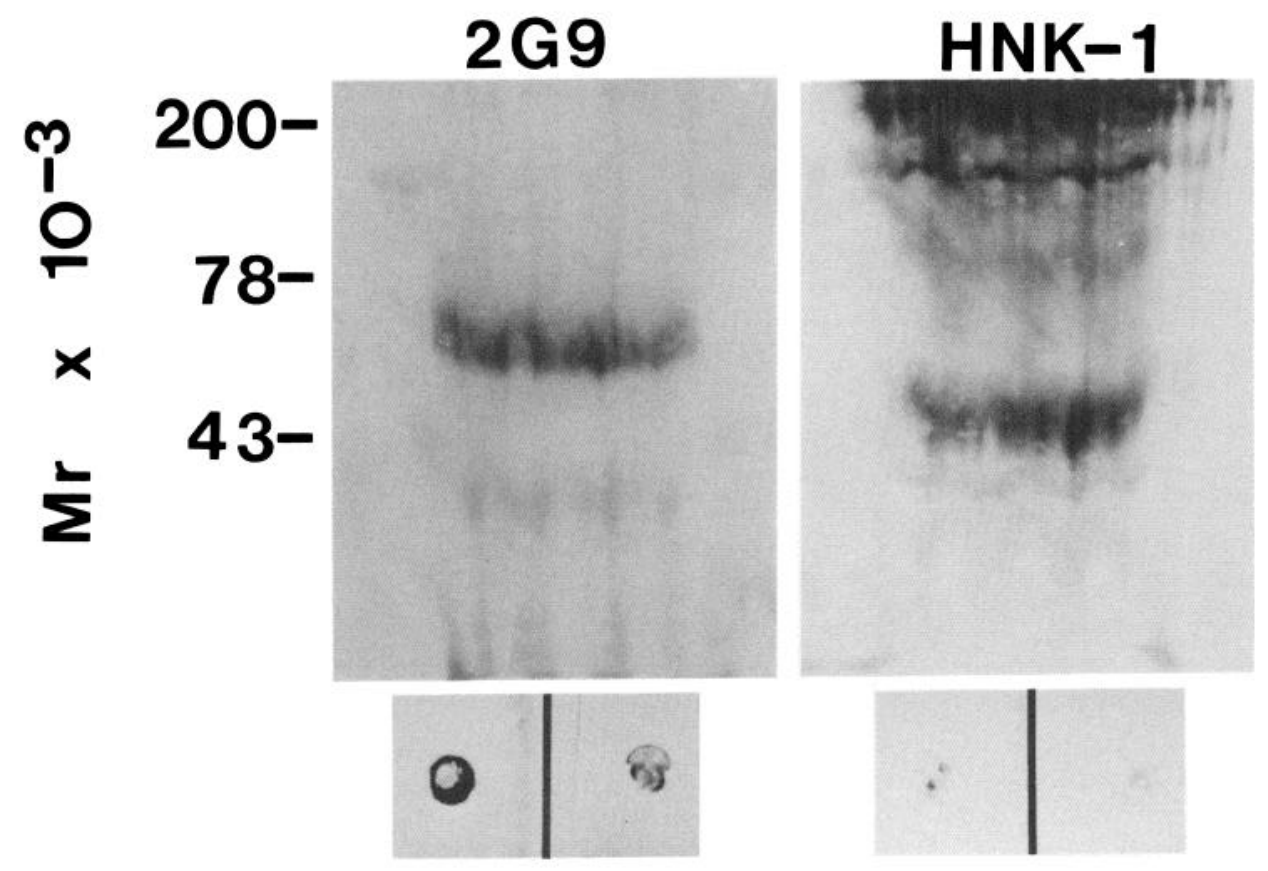

Figure 6. Western blot of Chaps-solubilized rat hippocampal membranes. Half of the blot was exposed to antiLAMP (monoclonal antibody $2 \mathrm{G} 9$ ) and the other half exposed to anti-HNK-1. Note the single, $64-68 \mathrm{kDa}$ protein band recognized by anti-LAMP, whereas antiHNK-1 cross-reacts with a large number of proteins above $100 \mathrm{kDa}$ and one at $43 \mathrm{kDa}$. Anti-HNK-1 does not recognize a protein in the molecular-mass range of LAMP. Bottom panel illustrates a dot-blot assay of immunoaffinity-purified LAMP incubated with anti-LAMP ( 2 squares in left panel containing 2 and $1 \mu \mathrm{l}$ of sample) or antiHNK-1 (2 squares in right panel containing 2 and $1 \mu \mathrm{l}$ of sample). Note that only anti-LAMP cross-reacts with the purified protein. 

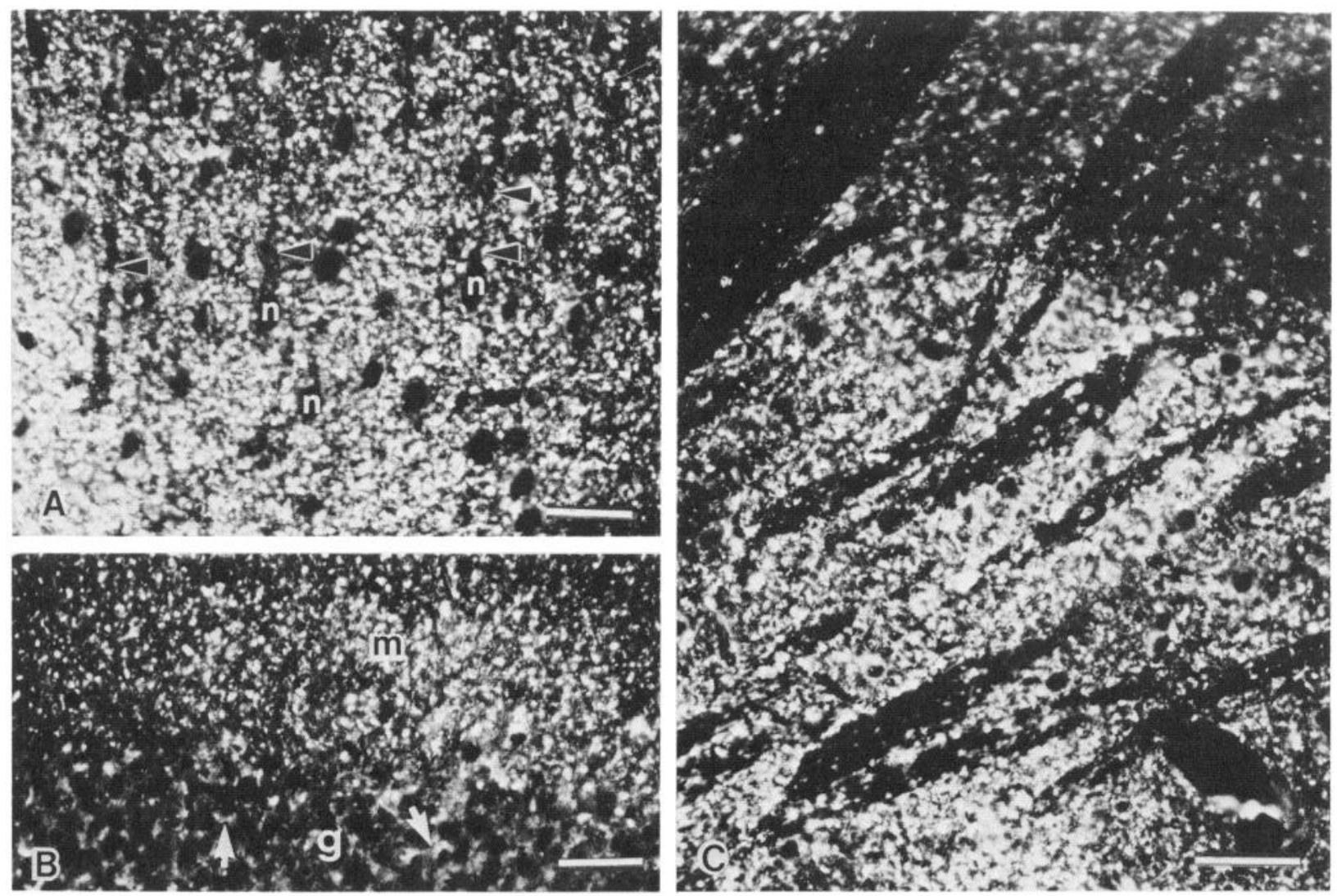

Figure 7. Immunofluorescence photomicrographs of LAMP localizaton in $(A)$ perirhinal cortex, $(B)$ dentate gyrus of the hippocampus, and $(C)$ posterior thalamic region. Immunoreactivity in each area appears punctate and is particularly dense in the neuropil. $A$, In the cortex, the unstained silhouettes of layer V pyramidal neurons $(n)$ and their apical dendrites (arrowheads) are surrounded by LAMP immunoreactivity. B, Pericellular staining (arrows) around dentate granule cells can be seen, in addition to punctate fluorescence in the molecular layer $(m)$. $C$, Fascicles of unstained axons can be seen coursing beween stained neuropil in this part of the thalamus. Scale bars, $20 \mu \mathrm{m}$.

in nonsynaptic zones on dendrites (Fig. 11, $A, B$ ), some profiles with a distinct synaptic complex contain LAMP immunoreactivity on the postsynaptic surface (Fig. 11A). Occasionally, cytoplasmic staining can be seen in dendritic processes. The HRP reaction product appears on microtubule structures, but this is usually present in profiles whose membranes are disrupted. In addition, outer mitochondrial membranes in stained profiles usually exhibit HRP reactivity. The localization to these structures presumably reflects nonspecific binding of HRP reaction product to certain cytoplasmic organelles (particularly the mitochondria), a phenomenon that is independent of the antigen being localized (cf. Levitt et al., 1981, for GFAP; DeCamilli et al., 1983, for synapsin I).

\section{LAMP localization on developing neurons}

Ultrastructural localization of LAMP in the developing postnatal brain reveals a pattern similar to our previous findings in fetal brain (Horton and Levitt, 1988). LAMP immunoreactivity is found on neuronal elements that are not stained in the adult, including axons and growth cones. In developing postnatal gray matter, LAMP immunoreactivity is found both pre- and postsynaptically. For example, during synaptogenesis in the lateral septum, LAMP staining is evident on terminal boutons and dendrites (Fig. 12, $A, C$ ). In many instances, profiles of immature presynaptic elements are also stained (Fig. 12B). Immunoreactivity usually is present at the pre- and postsynaptic specializations and along membranes that extend outside the synaptic zones. Synaptic vesicles are not LAMP-immunoreactive. This pre- and postsynaptic distribution differs from the adult, in which only the postsynaptic elements are immunoreactive.

\section{LAMP localization in cell cultures}

LAMP expression in hippocampal cultures is evident by $48 \mathrm{hr}$ after plating and continues to be expressed in cultures maintained for longer periods (up to $21 \mathrm{~d}$ ). The punctate surface distribution of LAMP, which is characteristic of the immunoreactivity in situ, is also prominent in both live and fixed cells (Figs. 13, 14). Thus, the epitope recognized by the monoclonal antibody is exposed on the extracellular side of the membrane. None of the LAMP-positive neurons exhibit cytoplasmic staining, either in fixed or unfixed specimens, further supporting our data demonstrating the specific association of LAMP with neuronal membranes. Immunostained neurons are found in aggregates (Fig. 13B) and as true monolayers (Fig. 13D) throughout the culture dish. LAMP-immunoreactive neurites form extensive arborizations throughout the culture. Fascicles of LAMPimmunoreactive neurites are often seen in mature cultures. Double-staining with anti-NF reveals that most of these long, unbranched neurites are axons that express LAMP (Fig. 13, $A$, $B$ ). Double-staining with anti-MAP-2 shows that dendritic processes also contain LAMP (Fig. 14). Colocalization of MAP-2 and LAMP occurs in many neurites that branch close to the cell soma. In some instances, neurons that are double-labeled with MAP-2 and LAMP (somata and their dendrites) contain single- 
labeled, LAMP-immunoreactive neurites, suggesting that these are axonal processes and, thus, the same neuron contains both a LAMP-immunoreactive dendrite and axons (Fig. 14). To determine whether astroglial cells in culture express LAMP, older cultures (greater than 1 week, when substantial GFAP expression occurs) were double-labeled with anti-LAMP and antiGFAP (Fig. 13, $C, D$ ). The patterns of LAMP and GFAP immunoreactivity are very distinct, and both GFAP-positive cell bodies and processes never appeared to be double-labeled with anti-LAMP.

\section{Discussion}

\section{Relation to the HNK-1 and NCAM families}

This study provides biochemical evidence that LAMP is a single, integral membrane glycoprotein that contains $\mathrm{N}$-linked high mannose carbohydrate chains with a small amount of sialic acid but does not contain the sulfated glucuronyl moiety, which is characteristic of the L2/HNK-1 family of adhesion glycoproteins (Abo and Balch, 1981). Treatment of a small amount of immunoaffinity-purified LAMP with trifluoromethane sulfonic acid (TFMS) resulted in a loss of protein beyond detection. Thus, we cannot determine at this time whether LAMP contains O-linked carbohydrate moieties. In addition to the analysis with anti-HNK-1 and deglycosylation enzymes, the molecular mass and $\mathrm{p} I$ determinations also indicate that LAMP is distinct from other cell surface molecules in the L2/HNK-1 and NCAM families. The fact that LAMP is expressed only in the CNS and has an anatomical distribution that is unique (Levitt, 1984) also support our suggestion that LAMP is a distinct molecular entity from other previously identified neuronal cell surface adhesion proteins.

Several lines of evidence suggest that LAMP is a unique brainspecific membrane protein. Immunocytochemical mapping reveals that LAMP is found mostly in limbic system-associated regions, both during development (Horton and Levitt, 1988) and in adults (Levitt, 1984). One hallmark of LAMP is expression on subsets of axons (Horton and Levitt, 1988), whereas NCAM and the L1 family are expressed more widely in axon pathways throughout the CNS during development (Beasley and Stallcup, 1987). The absence of LAMP in developing peripheral nerve pathways and in some central fiber tracks indicates that it is not identical to any of the known surface glycoproteins. The present biochemical findings correlate strongly with our previous anatomical analysis. The NCAM-related, calcium-independent family of cell surface glycoproteins is characterized by peptides that contain polysialydated sites (10-30\%) and have a molecular mass in the range of 120-220,000 Da. The molecular mass of LAMP, identified under reduced and nonreduced conditions, is far smaller than any of these peptides and contains an apparently modest amount of sialic acid, based on the shift following neuraminidase treatment of LAMP. LAMP also does not appear to be identical to the axonally distributed, L1-related cell surface glycoproteins in the HNK-1 family. Most of the peptide components range in molecular mass between 135230,000 Da (Salton et al., 1983; Grumet and Edelman, 1984; Rathjen and Schachner, 1984; Lemmon and McLoon, 1986; Wolff et al., 1987) and contain a common carbohydrate component (HNK-1) that cross-reacts with a single monoclonal antibody. Newly identified TAG-1 also falls into this family, with a molecular weight of 135-140,000 Da (Dodd et al., 1988). The molecular mass of immunopurified LAMP is well below any of these proteins and, as demonstrated in both Western blots and
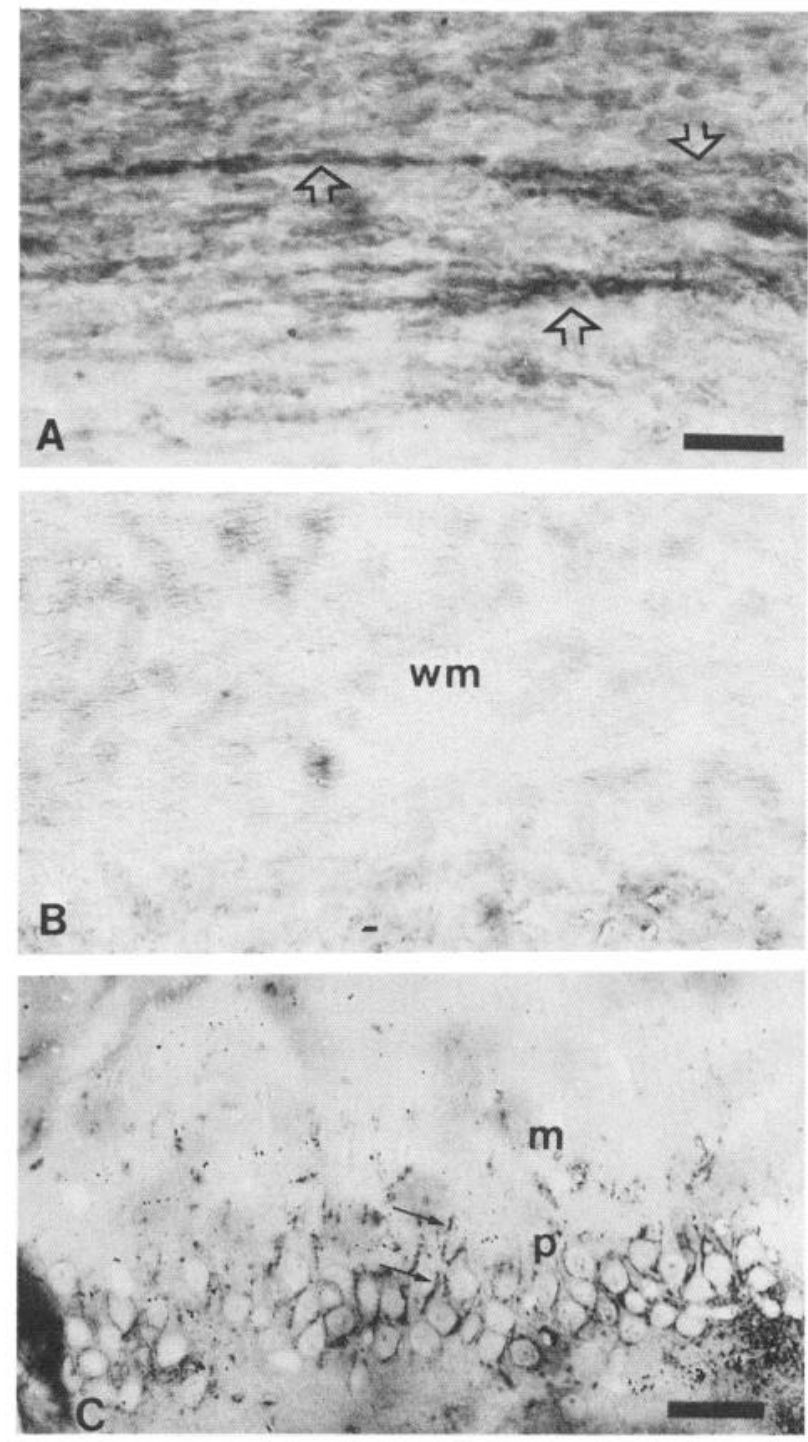

Figure 8. Immunoperoxidase staining of LAMP in the subcortical white matter at birth $(A)$ and postnatal day $28(B)$. Thick fascicles of LAMP-positive fibers (open arrows) are evident during development. This same region of white matter $(w m)$ in the mature brain does not stain with anti-LAMP. $C$, Pericellular localization of LAMP immunoreactivity in $1-\mu \mathrm{m}$-thick plastic section from CA2 region of Ammon's horn in adult rat. Note that almost all pyramidal neurons $(p)$ exhibit immunoreactive surfaces. In this section, only spotty staining is seen in the molecular layer. Scale bars: $20 \mu \mathrm{m}(A, B)$ and $35 \mu \mathrm{m}(C)$.

with affinity-pure LAMP, the HNK-1 carbohydrate epitope is not expressed by LAMP. A third group of developmentally regulated, axon-associated glycoproteins has been identified in the grasshopper (Snow et al., 1987). These proteins range in molecular mass from 37-95,000 Da, and one has sequence homology to the Ig superfamily (Harrelson and Goodman, 1988). Recent isolation and partial sequence analysis of a cDNA clone encoding LAMP(Pennypacker et al., 1989) indicates that LAMP has little sequence homology to any known protein, including the Ig superfamily of membrane proteins (Williams, 1982, 1987). While our data suggest that LAMP is not identical to any of the previously identified neuronal membrane glycoproteins, we currently cannot exclude the possibility that some homology be- 


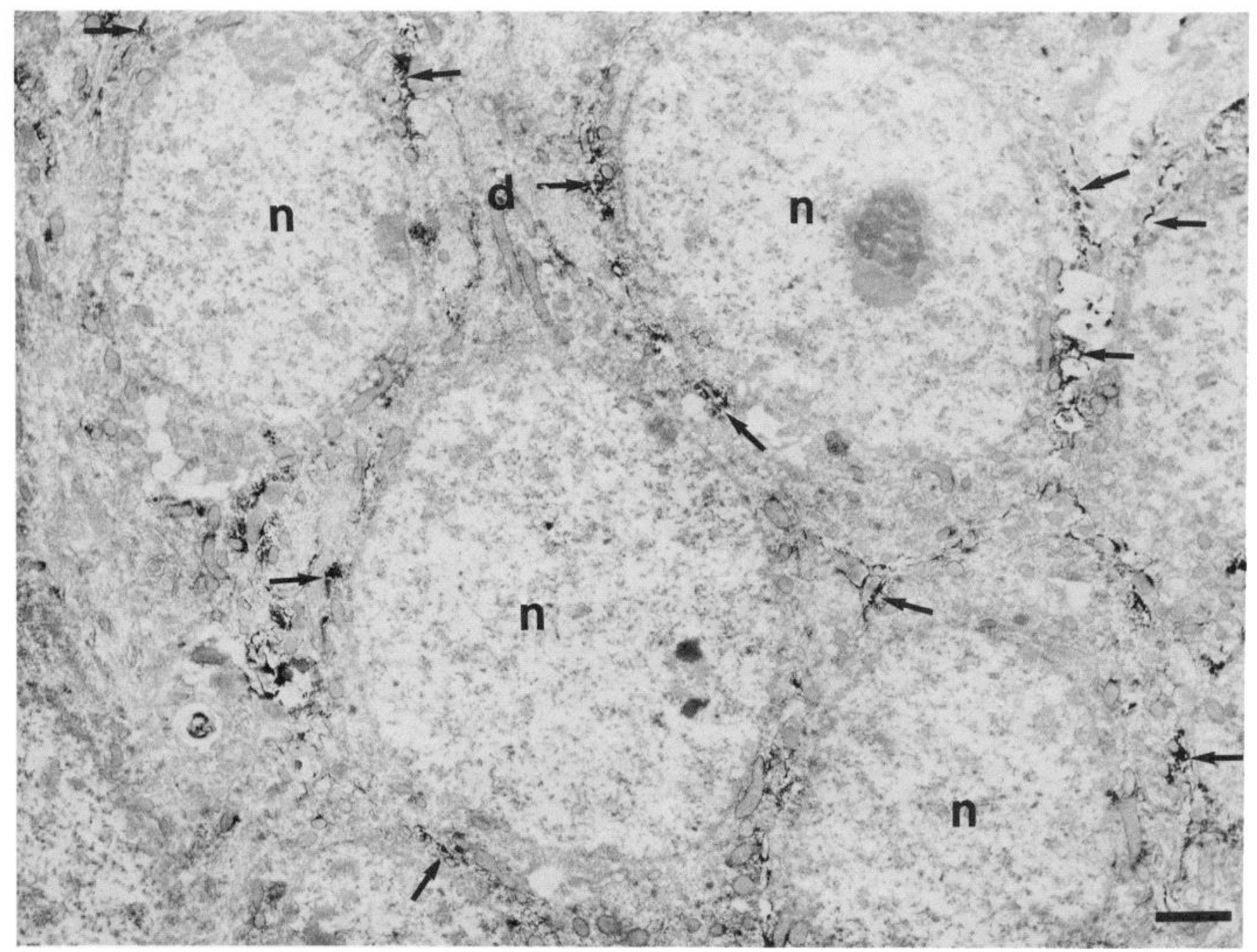

Figure 9. Granule cells of the dentate gyrus in adult hippocampus stained for LAMP. Electron micrograph reveals patchy staining (arrows) along the membranes of all granule cell somata in this plane of section. One primary dendrite $(d)$ can be seen and also is LAMP-positive. $n$, nucleus. Scale bar, $1 \mu \mathrm{m}$.

tween peptides may exist. This awaits additional sequence analysis of the cDNA clone and direct sequencing of LAMP.

\section{Spatial heterogeneity of LAMP}

The specific and restricted expression of LAMP to particular membrane compartments appears to be a developmentally regulated event. The distribution of surface molecules to select membrane regions of a cell has been well documented. The $\mathrm{ACh}$ receptor is initially expressed in patches throughout developing muscle cell but becomes redistributed to specific, localized sites during the process of maturation when innervation occurs (Bevan and Steinbach, 1977, Steinbach, 1981). There are several examples of proteins that are inserted into specific membrane domains of epithelial cells (Rodriguez-Boulan et al., 1983; Simons and Fuller, 1985; Ojakian and Schwimmer, 1988), conferring a molecular polarity to the cells. In the nervous system, unique glycoproteins recently have been shown to be specifically associated (though not exclusively) with growth cone membranes in mammals (Ellis et al., 1985; Meiri et al., 1986; Skene et al., 1986; Pfenninger, 1987), fascicles of axons and their growth cones in the invertebrate nervous system (Hockfield and McKay, 1983; McKay et al., 1983; Bastiani et al., 1987), and most recently in nonfasciculated commissural axons of the rodent spinal cord (Dodd et al., 1988). In the visual system, CAT-301, a membrane-associated high-molecular-weight proteoglycan (Zaremba et al., 1989) is expressed late in development (Sur et

Figure 10. A, Neuron in the nucleus of the solitary tract (adult) exhibits identical distribution of LAMP immunoreactivity as limbic neurons in the forebrain. Pericellular patches of somal staining are indicated by arrows. B, Neuron and several glial cells $(g)$ in the mediodorsal nucleus of the thalamus in close apposition to a blood vessel. The dendrite of the neuron shown in the electron micrograph courses around the glial cells that are in direct contact with the endothelial lining of the blood vessel. Only the dendritic membrane is LAMP-immunoreactive, whereas all the glial membranes that are not directly apposed to a dendritic patch of staining are LAMP-negative (for example, between the glial cells). Scale bars, $0.5 \mu \mathrm{m}$. 

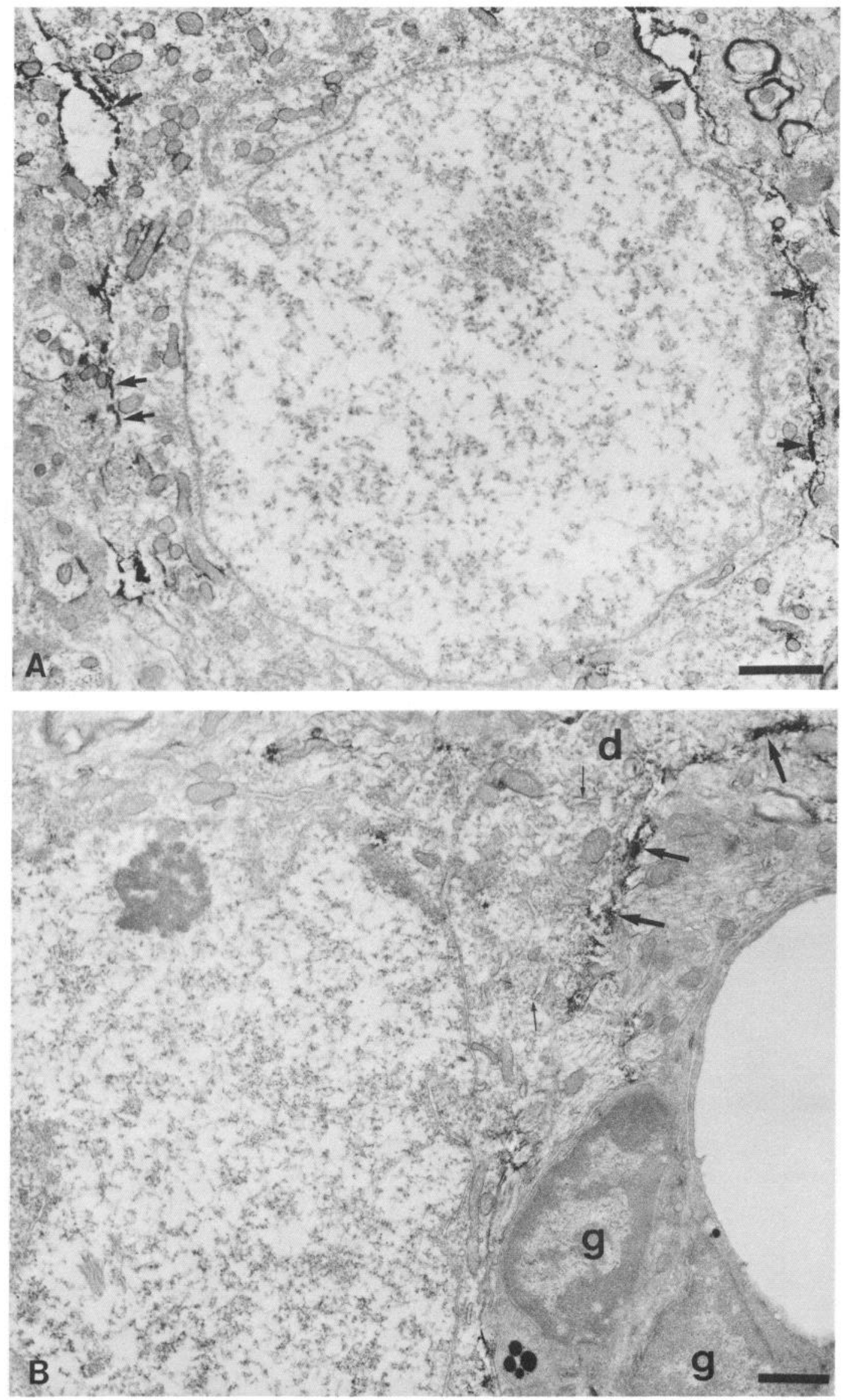

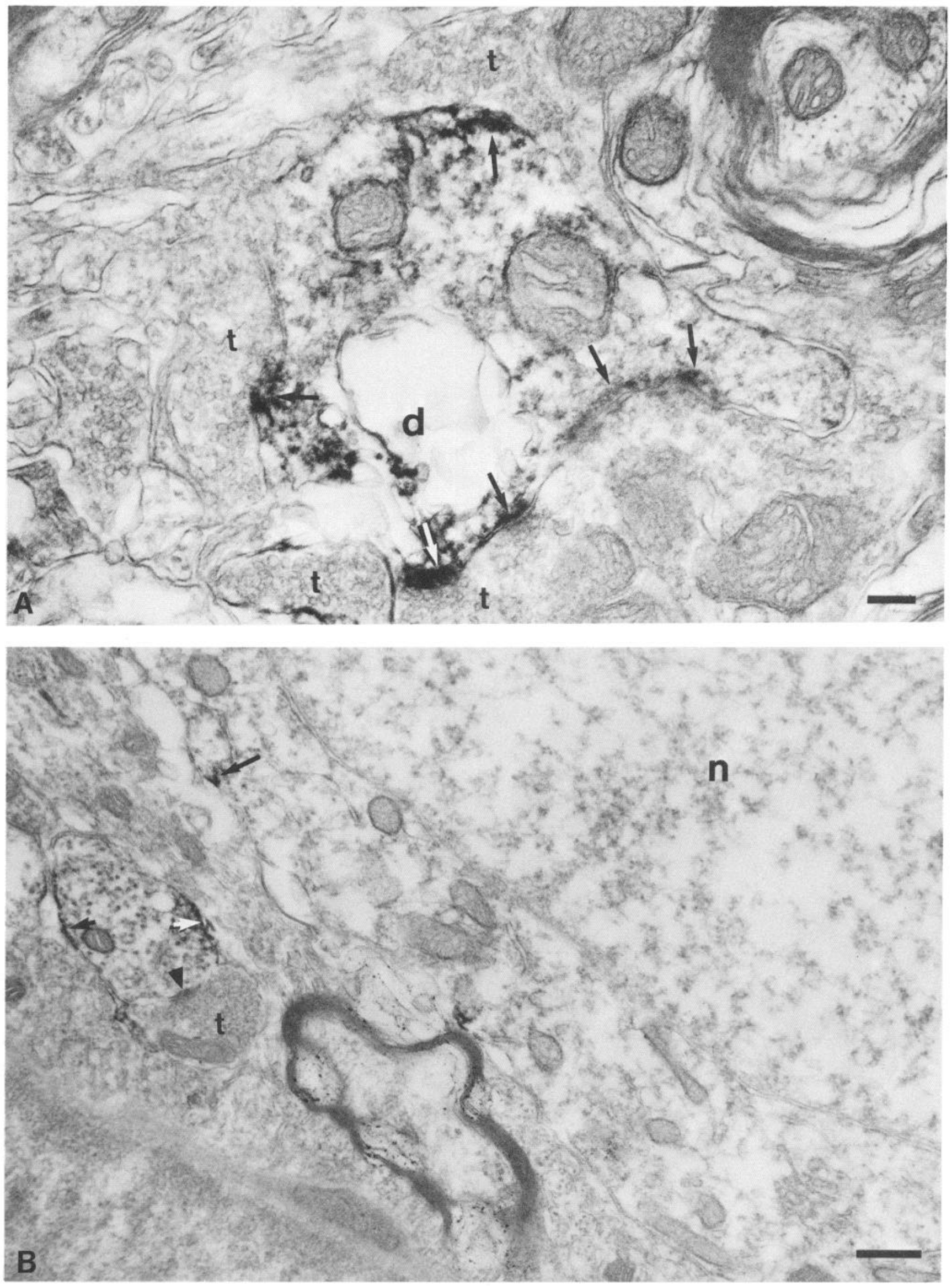

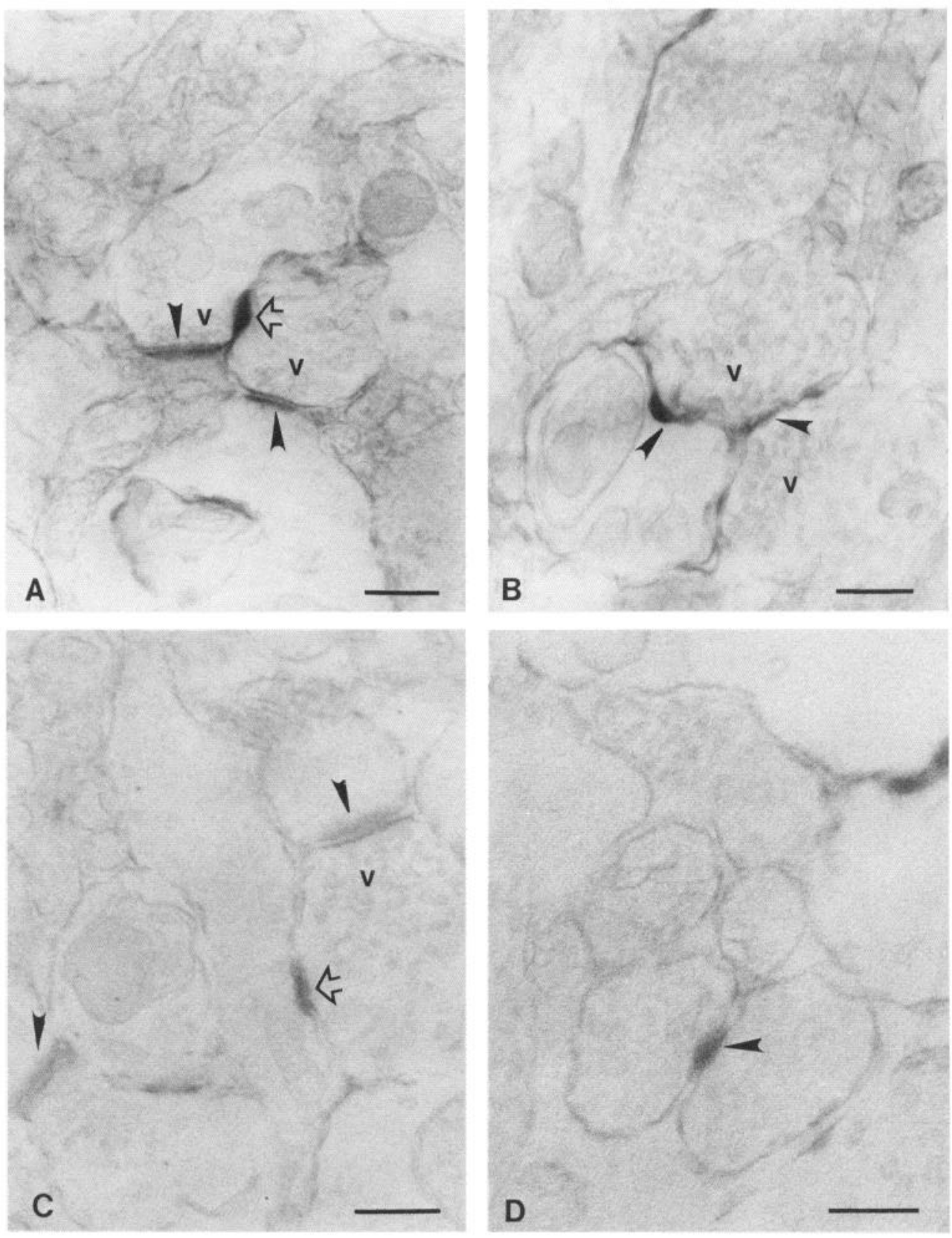

Figure 12. Electron micrographs from postnatal day 10 lateral septum. During this period of synaptogenesis, examples of immunoreactivity can be seen on presynaptic boutons in addition to postsynaptic dendrites. $A$, Two synapses, containing vesicles $(v)$ are LAMP-immunoreactive at the junctional complex (arrowheads), both pre- and postsynaptically. HRP reaction product is also present along their lateral surfaces (open arrow). $B$, Immature-looking presynaptic boutons contain vesicles $(v)$ and dense LAMP immunoreactivity along their membranes. $C$, Pre- and postsynaptic elements of 2 synapses are stained (arrowheads), as well as the lateral surfaces of the boutons (open arrow). $D$, LAMP immunoreactivity of 2 profiles that contain unstained vesicles. These may represent immature boutons or axonal profiles. Scale bars: $0.25 \mu \mathrm{m}(A-$ $C)$ and $0.1 \mu \mathrm{m}(D)$. al., 1988) and is specifically found around junctional complexes (Hockfield and McKay, 1983). Thus, in contrast to LAMP, these membrane proteins are targeted to specific microdomains from the onset of expression. The M6 glycoprotein appears to undergo modifications in trafficking in a manner similar to LAMP. M6 is inserted along the entire length of optic axons during devel- opment but is restricted to the optic fiber layer in adults (Lund et al., 1986).

LAMP exhibits differential developmental regulation because limbic system neurons clearly sort this glycoprotein differently during development than in the adult. A recent ultrastructural immunocytochemical analysis of the fetal rat brain revealed that

Figure 11. Higher-power electron micrographs from the central nucleus of the amygdala $(A)$ and lateral septum $(B)$ in an adult brain. $A$, Dendrite $(d)$ receiving a large number of terminals $(t)$ exhibits LAMP immunoreactivity along the membrane encompassing the postsynaptic density (arrows). Note the absence of staining in the presynaptic terminals. This is particularly evident on parts of the terminal membrane that do not directly appose the dendrite. The dendrite in this field exhibits some structural damage, which often accompanies large accumulation of HRP reaction product. Scale bar, $0.25 \mu \mathrm{m}$. B, A single synaptic complex is illustrated in this electron micrograph. The postsynaptic density appears unstained (black arrowhead), whereas the dendritic membrane patches that are unapposed to the terminal $(t)$ are LAMP immunoreactive (short black-and-white arrows). Note the absence of staining on the membrane of the terminal bouton. The edge of a neuron $(n)$ is also in this field and has a small patch of staining along its membrane (long arrow). Scale bar, $0.5 \mu \mathrm{m}$. 

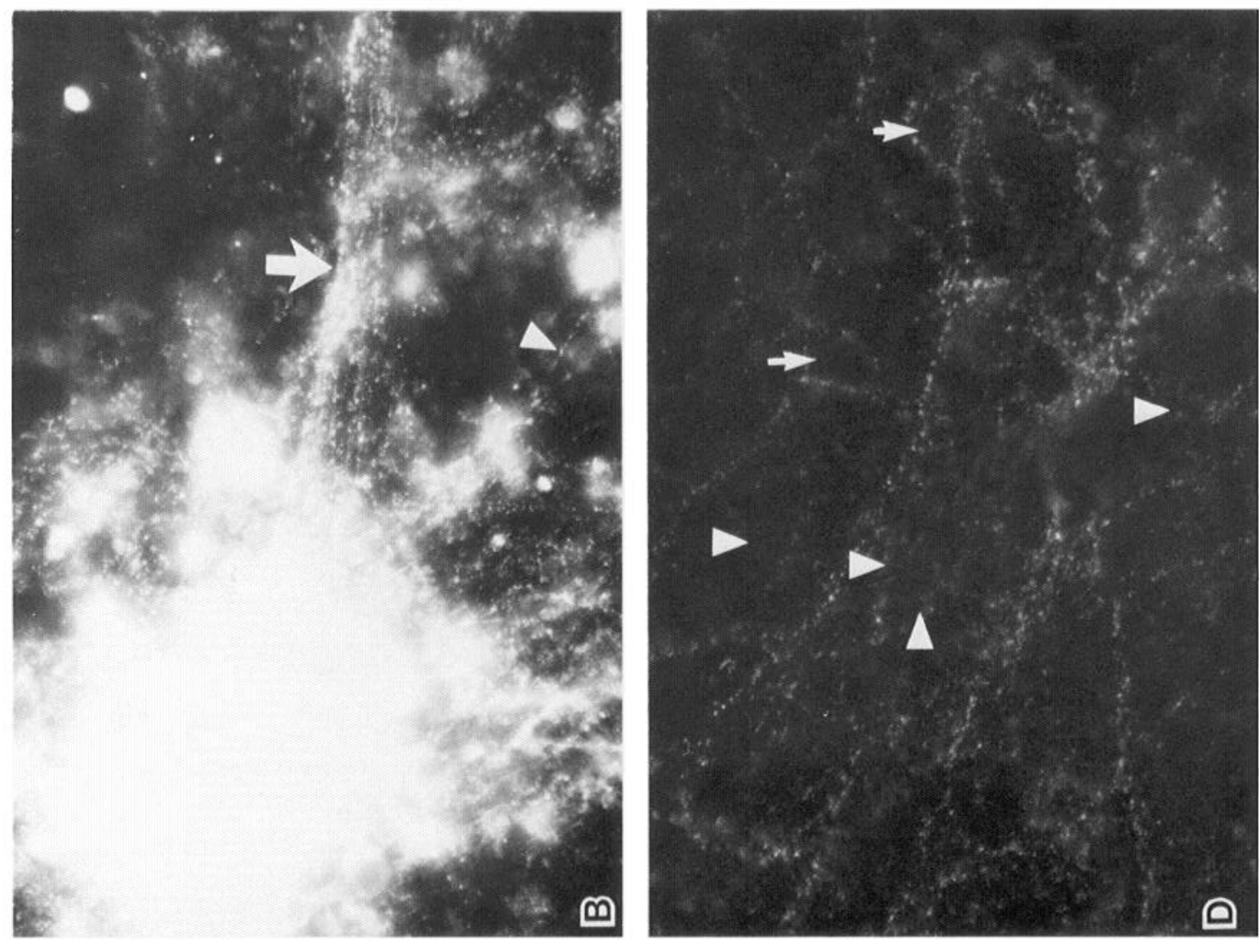

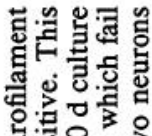

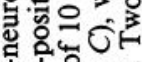

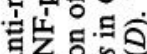

击

․․․

敦高

ठ5

月 च

马บ

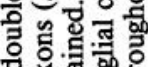

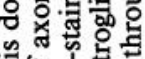

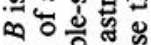

을

드융용

$\checkmark$ 品.

$.9<$ 졍 홍

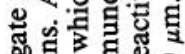

잉

政

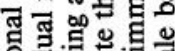

을

5 드요

z

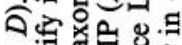

U

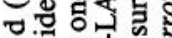

ㅇㅇ월

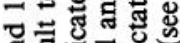
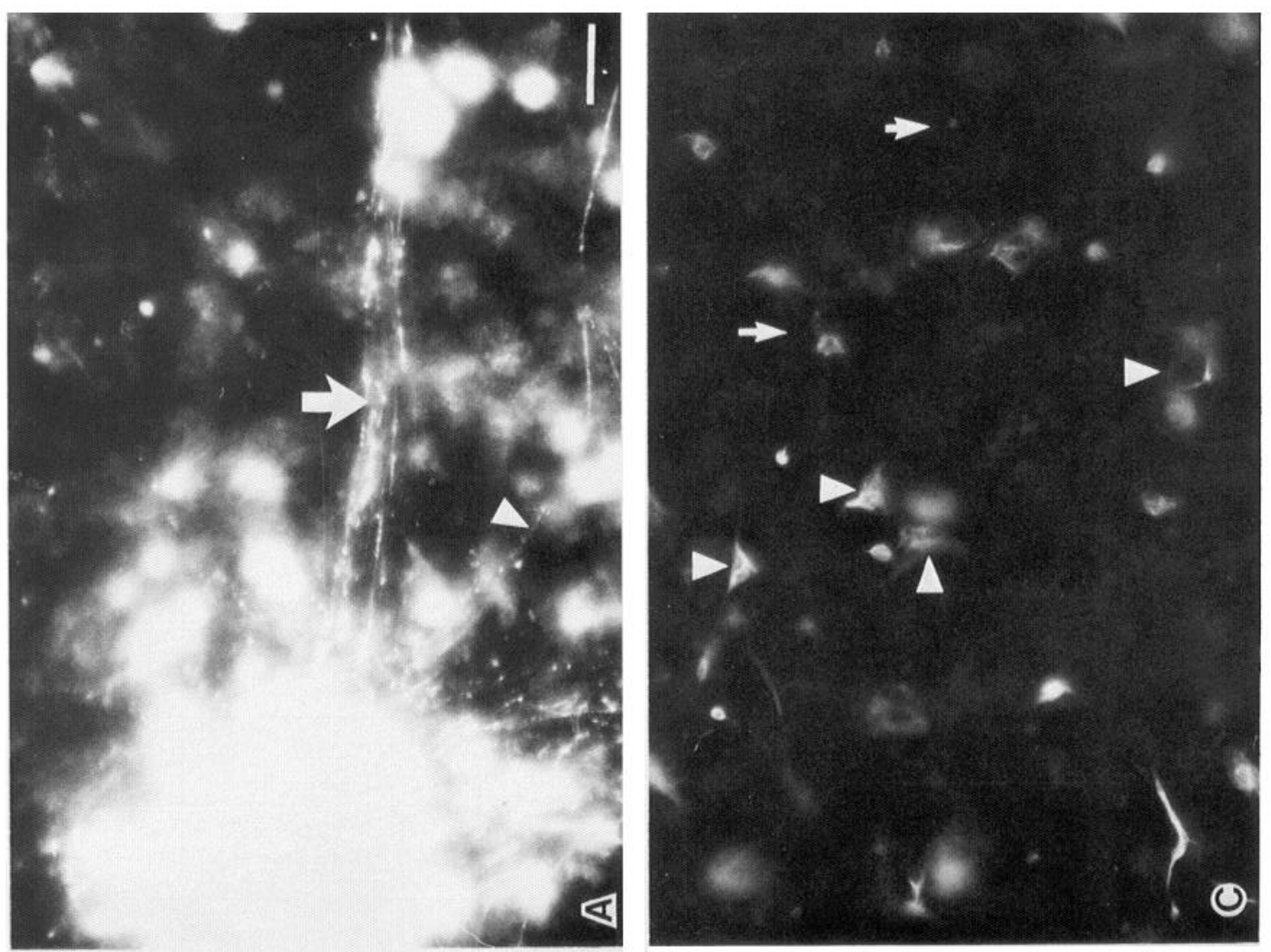

를

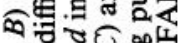
x.: 8 . 영 중ํㅀ 政 这尔密

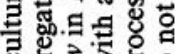
0

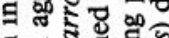

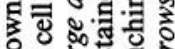
品 पै 을 。․ㄹ त

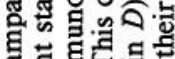
도의 을  当是西 원영 不同远 त त 으. on 等 药 눙

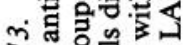

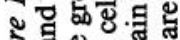
今ั

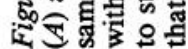




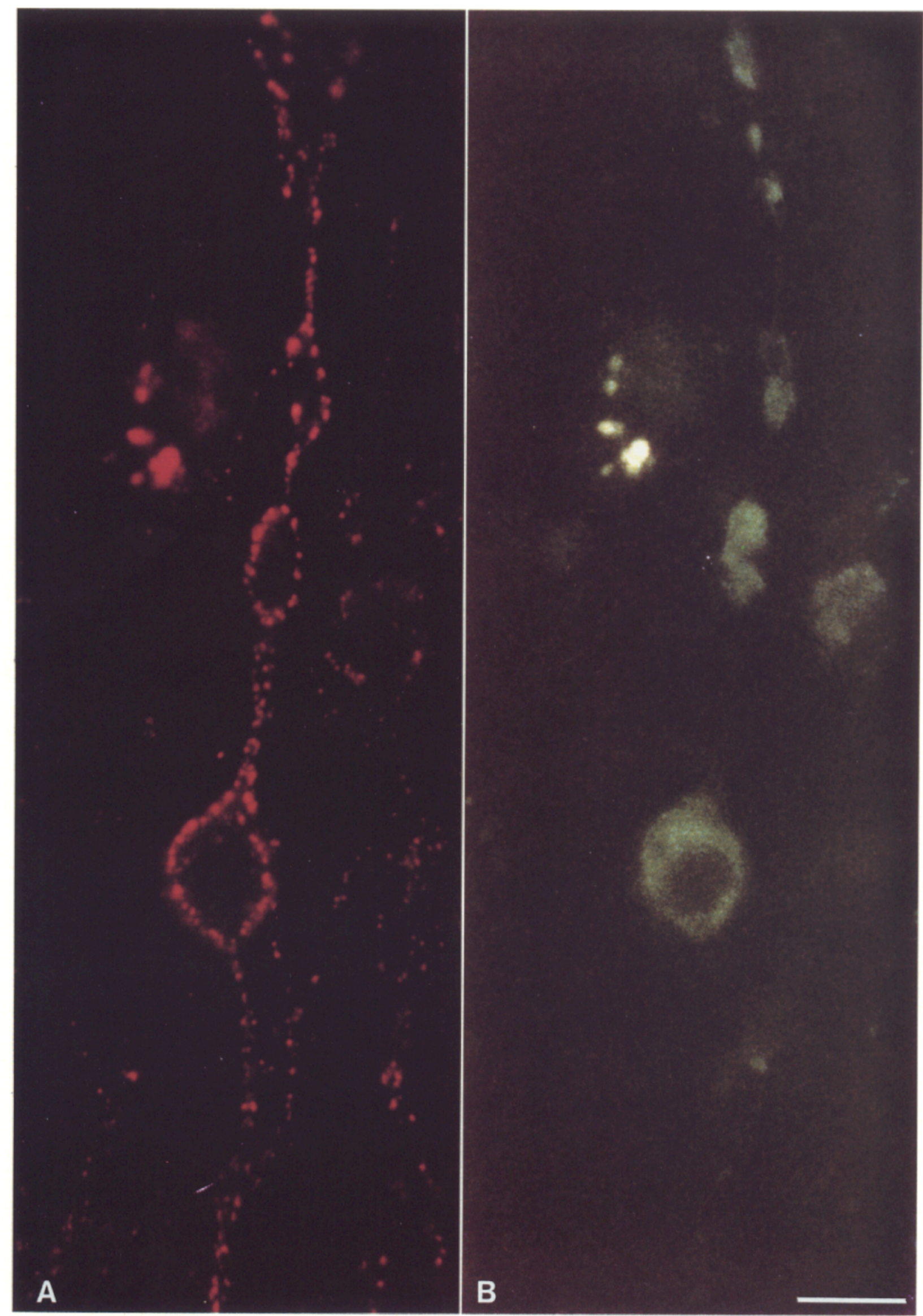

Figure 14. Color photomicrographs show a single hippocampal neuron, in culture for $48 \mathrm{hr}$, double-stained with anti-LAMP while alive $(A$; rhodamine-labeled secondary antibody) and anti-MAP-2 following fixation ( $B$; fluorescein-labeled secondary antibody). Note the punctate, pericellular LAMP immunoreactivity along the cell soma and varicose dendrite, which is double-stained with MAP2, and a single process that probably corresponds to the neuron's axon (not stained with anti-MAP-2). Scale bar, $10 \mu \mathrm{m}$. 
LAMP immunoreactivity is present at the surface of neuronal somata, dendrites, axons, and even growth cones (Horton and Levitt, 1988). This supports our data from the present study in which analysis of cultured hippocampal neurons and developing postnatal brain tissue localized LAMP immunoreactivity as discrete patches on the membranes of all parts of developing neurons, including immature synaptic complexes. In addition, both immunoassay and immunocytochemical data demonstrated that LAMP expression in axons is transient, disappearing from axon tracts during the third postnatal week of development (Horton and Levitt, 1988). Neurons that express LAMP appear to be capable of modifying the process by which LAMP is inserted into different membrane microdomains, suggesting that LAMP may perform functions in the developing nervous system that are different from those in the mature brain.

\section{System-associated molecules in neural development}

LAMP represents onc of the few molccular constituents in the vertebrate nervous system that is expressed during development by neurons (and their axons) that ultimately become functionally interrelated anatomically and physiologically. The suggestion that such system-associated molecules exist was proposed by Sperry (1963) for the retinotectal system, and later modified by McKay et al. (1983) and Goodman et al. (1984) for the invertebrate and by Levitt (1985) for the vertebrate nervous system. Why has it been so difficult to identify such molecules? Molecules that mediate cellular interactions, for example adhesion, among heterogeneous neurons have been found to be highly prevalent during development. Thus, one would predict that this class of cell surface molecules might be the most likely to be identified with current immunological approaches. The system-associated molecules have been much more evasive, possibly because of their more restricted expression on subpopulations of neurons. The possibility that families of such molecules exist is supported by data obtained from developing invertebrates, in which a number of monoclonal antibodies were used which enabled identification of molecules distributed on subsets of neurons and axons (McKay et al., 1983; Bastiani et al., 1987; Patel et al., 1987; Snow et al., 1987). Our light and electron microscopic immunocytochemical studies in the developing rat brain also indicate that LAMP is expressed in a restricted and transient manner on axon tracts (Horton and Levitt, 1988), being maintained during maturation only on the neuronal somata and dendrites in limbic system regions. It is unclear whether TAG-1, a glycoprotein identified by Dodd et al. (1988), exhibits similar system-associated characteristics of organization.

Two potential mechanisms could account for generating system-associated molecular specificity. In the case of LAMP, it appears that this protein has a restricted distribution from the onset of expression during fetal development. Thus, biochemically related cell surface molecules may exist for other functionally related groups of neurons. This has been found in the olfactory system by Schwob and Gottlieb (1988). In the case of TAG-1, differential expression, on axonal subsets, of a single protein during distinct periods of development could generate a highly specific pattern of circuit formation. It is likely that multiple proteins exist that are regulated by a combination of these mechanisms. This is supported by 2 types of experiments. Perturbation studies in which antibodies against cell surface constituents are used to alter some defined developmental event (cell migration, axon outgrowth, synaptogenesis) often yield modest changes (Silver and Rutishauser, 1984; Thanos et al.,
1984; Fischer et al., 1986; Trisler et al., 1986; Chang et al., 1987; Rathjen et al., 1987b; Harrelson and Goodman, 1988; Kunemund et al., 1988). In a recent study using anti-LAMP, we were able to disrupt the ability of septal cholinergic axons to invade and collateralize in an appropriate target, the hippocampus, without affecting general fiber outgrowth (Keller and Levitt, 1987; Keller et al., 1989). Even in this experiment, however, the most dramatic changes resulted in a $48 \%$ reduction in the number of hippocampi that were innervated, although the extent of cholinergic axon arborization in those that were innervated was greatly reduced. These results with antibodies may simply reflect the complex molecular arrays that act in concert to mediate specific cell-cell interactions. Alteration of a single cell surface protein may never totally disrupt development, unless the manipulation is lethal. This is highlighted by a second, more recent approach in which deletion of the Fasciclin III gene in Drosophila results only in a very minor change in axon growth (Jacobs and Goodman as cited in Harrelson and Goodman, 1988). In fact, the axons that normally express this protein are still able to find their appropriate target. This more elegant genetic manipulation reveals a similar result to those obtained with antibodies. Combinatorial approaches, for example, altering molecules that exhibit restricted expression (LAMP, TAG1) and those that are more generally distributed (HNK-1 family), may result in more substantial developmental anomolies.

\section{References}

Abo, T., and C. M. Balch (1981) A differentiation antigen of human NK and $\mathrm{K}$ cells identified by a monoclonal antibody (HNK-1). J. Immunol. 127: 1024-1029.

Antonicek, H., E. Persohn, and M. Schachner (1987) Biochemical and functional characterization of a novel neuron-glia adhesion molecule that is involved in ncuronal migration. J. Ccll Biol. 104: 1587-1595.

Bastiani, M. J., A. L. Harrelson, P. M. Snow, and C. S. Goodman (1987) Expression of fasciclin I and II glycoproteins on subsets of axon pathways during neuronal development in grasshoppers. Cell 48: 745755.

Beasley, L., and W. B. Stallcup (1987) The nerve growth factor-inducible large external (NILE) glycoprotein and neural cell adhesion molecule (NCAM) have distinct patterns of expression in the developing rat central nervous system. J. Neurosci. 7: 708-715.

Bevan, S., and J. H. Steinbach (1977) The distribution of $\alpha$-bungarotoxin binding sites on mammalian skeletal muscle developing in vivo. J. Physiol. (Lond.) 267: 195-213.

Bordier, C. (1981) Phase separation of integral membrane proteins in Triton X-114 solution. J. Biol. Chem. 256: 1604-1607.

Bronncr-Frascr, M. (1985) Altcrations in ncural crest cell migration by a monoclonal antibody that affects cell adhesion. J. Cell Biol. 101: 610-617.

Chang, S., F. G. Rathjen, and J. Raper (1987) Extension of neurites on axons is impaired by antibodies against specific neural cell surface glycoproteins. J. Cell Biol. 104: 355-362.

DeCamilli, P., M. Harris, Jr., W. B. Huttner, and P. Greengard (1983) Synapsin I (protein I), a nerve terminal-specific phosphoprotein. II. Its specific association with synaptic vesicles demonstrated by immunocytochemistry in agarose-embedded synaptosomes. J. Cell Biol. 96: 1355-1373.

Dodd, J., and T. M. Jessell (1988) Axon guidance and the patterning of neuronal projections in vertebrates. Science 242: 692-699.

Dodd, J., S. B. Morton, D. Karagogeos, M. Yamamoto, and T. M. Jessell (1988) Spatial regulation of axonal glycoprotcin cxpression on subsets of embryonic spinal neurons. Neuron 1: 105-116.

Edelman, G. M. (1984) Cell-surface modulation and marker multiplicity in neural patterning. TINS 69: 79-84.

Edmondson, J. C., R. K. H. Liem, J. E. Kuster, and M. E. Hatten (1988) Astrotactin: A novel neuronal cell surface antigen that mediates neuron-astroglial interactions in cerebellar microcultures. J. Cell Biol. 106: 505-517.

Ellis, L., I. Wallis, E. Abreu, and K. H. Pfenninger (1985) Nerve growth cones isolated from fetal rat brain. IV. Preparation of a membrane 
subfraction and identification of a membrane glycoprotein expressed on sprouting neurons. J. Cell Biol. 101: 1977-1989.

Fairbanks, G., T. L. Steck, and D. F. H. Wallach (1971) Electrophoretic analysis of the major polypeptides of the human erythrocyte membrane. Biochemistry 10: 2026-2047.

Fischer, G., V. Kunemund, and M. Schachner (1986) Neurite outgrowth patterns in cerebellar microexplant cultures are affected by antibodies to the cell surface glycoprotein L1. J. Neurosci. 6: 605612.

Fraser, S. E., B. A. Murray, C.-M. Chuong, and G. M. Edelman (1984) Alterations of the retinotectal map in Xenopus by antibodics to ncural cell adhesion molecules. Proc. Natl. Acad. Sci. USA 81: 4222-4226.

Fridovich, I. (1963) Stimulation of horseradish peroxidase by nitrogenous ligands. J. Biol. Chem. 238: 3921-3927.

Goodman, C. S., M. J. Bastiani, C. Q. Doe, S. du Lac, S. L. Helfand, J. Y. Kuwada, and J. B. Thomas (1984) Cell recognition during neuronal development. Science 225: 1271-1279.

Greenberger, L. M., and K. H. Pfenninger (1986) Membrane glycoproteins of the nerve growth cone: Diversity and growth regulation of oligosaccharides. J. Cell Biol. 103: 1369-1382.

Grumet, M., and G. M. Edelman (1984) Heterotypic binding between neuronal membrane vesicles and glial cells is mediated by a specific cell adhesion molecule. J. Cell Biol. 98: 1746-1756.

Harrelson, A. L., and C. S. Goodman (1988) Growth cone guidance in insects: Fasciclin II is a member of the immunoglobulin superfamily. Science 242: 700-705.

Hawkes, R., E. Niday, and J. Gordon (1982) A dot-immunobinding assay for monoclonal and other antibodies. Anal. Biochem. 119: 142147.

Hockfield, S., and R. D. G. McKay (1983) A surface antigen expressed by a subset of neurons in the vertebrate central nervous system. Proc. Natl. Acad. Sci. USA 80: 5758-5761.

Horton, H. L., and P. Levitt (1988) A unique membrane protein is expressed on early developing limbic system axons and cortical targets. J. Neurosci. 8: 4653-4661.

Jessell, T. M. (1988) Adhesion molecules and the hierarchy of neural development. Neuron 1: 3-13.

Kasten, F. H. (1960) The chemistry of Schiff's reagent. Int. Rev. Cytol. 10: $1-100$.

Keller, F., and P. Levitt (1987) Developmental and growth-associated regulation of the limbic system-associated membrane protein in brain explant cultures. Soc. Neurosci. Abstr. 13: 1145.

Keller, F., and P. Levitt (1989) Developmental and regeneration-associated regulation of the limbic system-associated membrane protein in explant cultures of the rat brain. Neuroscience 28: 455-474.

Keller, F., K. Rimvall, M. F. Barbe, and P. Levitt (1989) A membrane glycoprotein associated with the limbic system mediates the formation of the septo-hippocampal pathway in vitro. Neuron 2: 551-561.

Kruse, J., R. Mailhammer, H. Wernecke, A. Faissner, I. Sommer, C. Goridis, and M. Schachner (1984) Neural cell adhesion molecules and myelin-associated glycoproteins share a common carbohydrate moiety recognized by monoclonal antibodies L2 and HNK-1. Nature 311: 153-155.

Kunemund, V., F. B. Jungalwala, G. Fischer, D. K. H. Chou, Keilhauer, and $M$. Schachner (1988) The L2/HNK-1 carbohydrate of neural cell adhesion molecules is involved in cell interactions. J. Cell Biol. 106: 213-223.

Laemmli, U. K. (1970) Cleavage of structural proteins during the assembly of the head of bacteriophage T4. Nature 227:680-685.

Lagenaur, C., and V. Lemmon (1987) An L1-like molecule, the 8D9 antigen, is a potent substrate for neurite extension. Proc. Natl. Acad. Sci. USA 84: 7753-7757.

Lander, A. D. (1987) Molecules that make axons grow. Mol. Neurobiol. 1: 213-245.

Lemmon, V., and S. C. McLoon (1986) The appearance of an L1-like molecule in the chick primary visual system. J. Neurosci. 6: 29872994.

Levitt, P. (1984) A monoclonal antibody to limbic system neurons. Science 223: 299-301.

Levitt, P. (1985) Relating molecular specificity to normal and abnormal brain development. Ann. NY Acad. Sci. 450: 239-246.

Levitt, P., M. L. Cooper, and P. Rakic (1981) Coexistence of neuronal and glial precursor cells in the cerebral ventricular zone of the fetal monkey: An ultrastructural immunoperoxidase analysis. J. Neurosci. 1: 27-39.

Levitt, P., E. Pawlak-Byczkowska, H. L. Horton, and V. Cooper (1986)
The assembly of functional systems in the brian: Molecular and anatomical studies of the limbic system. In Neurobiology of Down Syndrome, C. J. Epstein, ed., pp. 195-210, Raven, New York.

Lund, R. D., V. H. Perry, and C. F. Lagenaur (1986) Cell surface changes in the developing optic nerve. J. Comp. Neurol. 247: 439446.

McKay, R. D. G., S. Hockfield, J. Johanson, I. Thompson, and K. Frederickson (1983) Surface molecules identify groups of growing axons. Science 222: 788-794.

Meiri, K. F., K. H. Pfenninger, and M. B. Willard (1986) Growthassociated protein, GAP-43, a polypeptide that is induced when neurons extend axons, is a component of growth cones and corresponds to pp46, a major polypeptide of a subcellular fraction enriched in growth cones. Proc. Natl. Acad. Sci. USA 83: 3537-3541.

Moos, M., R. Tacke, H. Scherer, D. Teplow, K. Fruh, and M. Schachner (1988) Neural adhesion molecule Ll as a member of the immunoglobulin superfamily with binding domains similar to fibronectin. Nature 334: 701-703.

Morrissey, J. H. (1981) Silver stain for proteins in polyacrylamide gels: A modified procedure with enhanced uniform sensitivity. Anal. Biochem. 117: 307-310.

O'Farrell, P. H. (1975) High resolution two-dimensional electrophoresis of proteins. J. Biol. Chem. 250: 4007-4021.

Ojakian, G. K., and R. Schwimmer (1988) The polarized distribution of an apical cell surface glycoprotein is maintained by interactions with the cytoskeleton of Madin-Darby canine kidney cells. J. Cell Biol. 107: 2377-2387.

Patel, N. H., P. W. Snow, and C. S. Goodman (1987) Characterization and cloning of fasciclin III: A glycoprotein expressed on a subset of neurons and axon pathways in drosophila. Cell 48: 975-988.

Pennypacker, K. R., B. Bhardwaj, P. Levitt, and B. Schepart (1989) Cloning of the cDNA encoding the limbic system-associated membrane protein (LAMP). Soc. Neurosci. Abstr. 15: 1268.

Pfenninger, K. H. (1987) Plasmalemmal properties of the sprouting neuron. Curr. Top. Dev. Biol. 21: 185-206.

Platt, J. L., and A. F. Michael (1983) Retardation of fading and enhancement of intensity of immunofluorescence by p-phenylenediamine. J. Histochem. Cytochem. 31:840-842.

Rathjen, F. G. (1988) A neurite outgrowth-promoting molecule in developing fiber tracts. TINS $11: 183-184$.

Rathjen, F. G., and M. Schachner (1984) Immunocytological and biochemical characterization of a new neuronal cell surface component ( $\mathrm{L} 1$ antigen) which is involved in cell adhesion. EMBO J. 3: 110.

Rathjen, F. G., J. M. Wolff, R. Frank, F. Bonhoeffer, and U. Rutishauser (1987a) Membrane glycoproteins involved in neurite fasciculation J. Cell Biol. 104: 343-353.

Rathjen, F. G., J. M. Wolff, S. Chang, F. Bonhoeffer, and J. A. Raper (1987b) Neurofascin: A novel chick cell-surface glycoprotein involved in neurite-neurite interactions. Cell 51: 841-849.

Rodriguez-Boulan, E., K. T. Paskiet, and D. D. Sabatini (1983) Assembly of enveloped viruses in MDCK cells: Polarized budding from single attached cells and from clusters of cells in suspension. J. Cell Biol. 96: 308-319.

Rutishauser, U. (1984) Developmental biology of a neural cell adhesion molecule. Nature 310: 549-554.

Rutishauser, U., A. Acheson, A. K. Hall, D. M. Mann, and J. Sunshine (1988) The neural cell adhesion molecule (NCAM) as a regulator of cell-cell interactions. Science 240: 53-57.

Salton, S. R., M. L. Shelanski, and L. A. Green (1983) Biochemical properties of the nerve growth factor-inducible large external (NILE) glycoprotein. J. Neurosci. 3: 2420-2430.

Schlosshauer, B. (1985) Membrane proteins and glycoproteins specific to central nervous system axons and growth cones. Dev. Brain Revs. 19: 237-244.

Schneider, C., R. A. Newman, D. R. Sutherland, U. Asser, and M. F. Grcaves (1982) A one-step purification of membrane proteins using a high efficiency immunomatrix. J. Biol. Chem. 257: 10766-10769.

Schwob, J. E., and D. I. Gottlieb (1988) Purification and characterization of an antigen that is spatially segregated in the primary olfactory projection. J. Neurosci. 8 : $3470-3480$.

Silver, J., and U. Rutishauser (1984) Guidance of optic axons in vivo by a preformed adhesive pathway on neuroepithelial endfeet. Dev. Biol. 106: 485-499.

Simons, K., and S. D. Fuller (1985) Cell surface polarity in epithelia. Annu. Rev. Cell Biol. 1: 243-288. 
Skene, J. H. P., R. D. Jacobson, G. J. Snipes, C. B. McGuire, J. J Norden, and J. A. Freeman (1986) A protein induced during nerve growth (GAP-43) is a major component of growth cone membranes. Science 233: 783-786.

Snow, P. M., N. H. Patel, A. L. Harrelson, and C. S. Goodman (1987) Neural-specific carbohydrate moiety shared by many glycoproteins in Drosophila and grasshopper embryos. J. Neurosci. 7: 4137-4144.

Sperry, R. W. (1963) Chemoaffinity in the orderly growth of nerve fiber patterns and connections. Proc. Natl. Acad. Sci. USA 50: 703710 .

Steinbach, J. H. (1981) Developmental changes in acetylcholine receptor aggregates at rat skeletal neuromuscular junctions. Dev. Biol. 84: 267-276.

Sur, M., D. O. Frost, and S. Hockfield (1988) Expression of a cell surface antigen on Y-cells in the cat lateral geniculate nucleus is regulated by visual experience. J. Neurosci. 8: 874-882.

Tarentino, A. L., R. B. Trimble, and F. Maley (1978) Endo-beta-nacetylglucosaminidase from Streptomyces plicatus. Methods Enzymol. $50: 574-580$.

Thanos, S., F. Bonhoeffer, and U. Rutishauser (1984) Fiber-fiber interaction and tectal cues influence the development of the chicken retinotectal projection. Proc. Natl. Acad. Sci. USA 81: 1906-1910.
Thierry, J. P., J.-L. Duband, and G. C. Tucker (1985) Cell migration in the vertebrate embryo. Annu. Rev. Cell. Biol. 1: 91-113.

Tosney, K. W., M. Watanabe, L. Landmesser, and U. Rutishauser (1986) The distribution of NCAM in the chick hindlimb during axon outgrowth and synaptogenesis. Dev. Biol. 114:437-452.

Towbin, H., T. Staehelin, and J. Gordon (1979) Electrophoretic transfer of proteins from polyacrylamide gels to nitrocellulose sheets: Proccdurc and some applications. Proc. Natl. Acad. Sci. USA 76: 43504354.

Trisler, D., J. Bekenstein, and M. P. Daniels (1986) Antibody to a molecular marker of cell position inhibits synapse formation in retina. Proc. Natl. Acad. Sci. USA 83: 4194-4198.

Williams, A. F. (1982) Surface molecules and cell interactions. J. Theor. Biol. 98: 221-234.

Williams, A. F. (1987) A year in the life of the immunoglobulin superfamily. Immunol. Today 8: 298-302.

Wolff, J. M., F. G. Rathjen, R. Frank, and S. Roth (1987) Biochemical characterization of polypeptide components involved in neurite fasciculation and elongation. Eur. J. Biochem. 168: 551-561.

Zaremba, S., A. Guimaraes, R. G. Kalb, and S. Hockfield (1989) Characterization of an activity-dependent neuronal surface proteoglycan identificd with monoclonal antibody Cat-301. Neuron 2: 1207-1219. 